\title{
Industria lítica en el megalitismo del Noroeste peninsular: consideraciones generales
}

\author{
RAMÓN FABREgas VALCARCE
}

Les morts cachés sont bien dans cette terre.

PAUL VALERY, Le cimetière marin.

ABSTRACT.-Lithic industry from the megalithic mounds of Galicia and Nort Portugal: A general view.

The artefacts made of flaked or ground stone, are the most common items among the grave-goods laid within the megalithic mounds of the study area (figs. 9-10). Unfortunately, these monuments have been too often thoroughfully plundered, while on other occasions they were not excavated in a scientifical way, therefore setting a limited scope to our analysis. In spite of that, we have found certain recurrent associations ( $v$. g. flint blades and arrow-heads; maces, hoe blades and chisels; geometrical microliths, beads, flakes and bladelets) that migth represent actual kits. Although differences among the several types of megalith regarding to the amount of lithic materials are not definite (fig. 4), the graves with a complex passage structure (fig. 3a) show a more varied array of lithic materials. Some items tend to occur more often in certain types of tomb: single chambers have, for instance, a relatively high amount of microliths, querns or flakes, passage-graves yielded more arrow-heads, axes and quartz prisms, while idols are typical of the tombs with complex passage 
structures. We have found that the coastal mounds as a whole show themselves wealthier than their counterparts inland. This gap seems to increase towards the middle part of the $3^{r d}$ millenium (in radiocarbon years) when certain items like arrowheads, large flint-blades or, less widespread, idols are particularly frequent among littoral monuments. A later development takes place in an area clustered around the Upper Miño valley, where some mounds have yielded maces, long chisels or hoe blades and, seldom, double adzes or double axes (lám. 1).

\section{INTRODUCCIÓN}

Aunque los túmulos han atraído una gran atención desde el mismo inicio de la Prehistoria como ciencia autónoma en el cuadrante noroccidental peninsular, suscitando ya a finales del siglo pasado numerosas exploraciones y catalogaciones comarcales, nuestro conocimiento sobre los diversos aspectos del fenómeno megalítico es todavia bastante parcial '. A ello contribuye por una parte la virtual ausencia hasta fechas recientes de estudios monográficos sobre apartados tan importantes como son la cultura material, el arte o la arquitectura ${ }^{2}$. Asimismo, habria que considerar el exceso de localismo que tine la casi totalidad de los trabajos llevados a cabo a uno y otro lado de la frontera política galaicoportuguesa, de forma que desde las grandes sintesis publicadas por F. López Cuevillas ${ }^{3}$ no se ha abordado de una forma conjunta el mega-

\footnotetext{
El trabajo que aqui se presenta es un resumen de nuestra Tesis Doctoral que con el titulo "Estudio de los ajuares líticos de las sepulturas megalíticas de Galicia y Norte de Portugal" fue leida el 20 de junio de 1990 en la Facultad de Geografia e Historia de la Universidad Nacional de Educación a Distancia. El director de la tesis fue el profesor doctor don Eduardo Ripoll Perelló. El tribunal, que le otorgó la máxima calificación. estaba formado por los profesores doctor don German Delibes de Castro (presidente). doctora doña Maria Luisa Ruiz-Gálvez Priego, doctor don Felipe Criado Boado. doctora dona Ana Fernández Vega y doctor don Sergio Ripoll López. No se abordará aqui el estudio pormenorizado de cada uno de los grandes tipos de artefactos líticos, limitandonos en esta ocasion a plasmar una visión de conjunto sobre dichos materiales.

No deja de ser curioso que sobre estos dos últimos temas las únicas sistematizaciones sean de autoría extranjera, una de ellas ya muy antigua. Estas son: LEISNER, G., Verbreitung und Typologie der galizisch-nordportugiesischen Megalithgräber. Marburg, 1938, en lo referente a la arquitectura megalítica del Noroeste, y SHEE TwOHIG. E.. The Megalithic Art of Western Europe, Oxford, 1981, para el arte.

"Lopez Cuevillas, F., "La época megalítica en el Noroeste de la Península", Caesaraugusta, 13-14. 1959, pags. 21-77.
} 


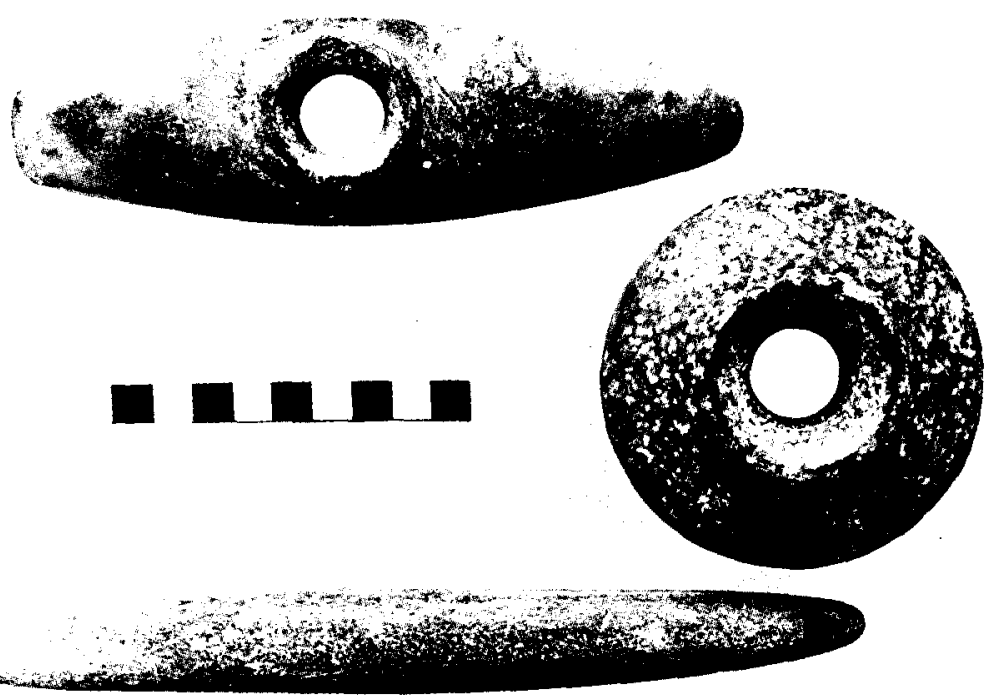

Lamina 1. Ajuar de un tumulo con camara rectangular de Veiga das Mamoas (Lugo): doble azuela, maza y cincel de piedra pulida.

litismo del Noroeste, ello a pesar del general consenso acerca de la básica unidad de sus manifestaciones en la amplia región que abarca desde el Ortegal al valle del Duero.

Los artefactos líticos configuran en sus diversos apartados el segmento mayoritario y más variado dentro de los materiales recuperados en el seno de las sepulturas tumulares del Noroeste peninsular. Es precisamente su representatividad en un contexto de ajuares con frecuencia cuantitativamente pobres, lo que nos ha llevado a abordar su estudio para el conjunto formado por Galicia y el Portugal al Norte del Duero. Este trabajo no ha estado exento de limitaciones, condicionantes y problemas, algunos de los cuales referiremos a continuación.

Un primer aspecto a considerar es la significación exacta que se debe otorgar al término megalítico. En realidad utilizaremos aquí dicha denominación con una calculada ambigüedad que nos permitirá incluir en nuestro estudio túmulos que o bien no contenian una cámara propiamente dicha, o bien ésta tenía unas proporciones tan pequeñas que haría inapropiado adjetivarla de megalítica en un sentido estricto. Su inclusión 
al lado de los demás monumentos ortostáticos viene motivada por la coincidencia global con estos últimos en cuanto a cronología y cultura material.

Los 87 monumentos objeto de análisis conforman una muestra que responde a un estado coyuntural de nuestro conocimiento, inmerso en la actualidad en una dinámica de cambio tal que obliga a revisar y completar cada poco tiempo las ideas que sobre este fenómeno se poseen en el Noroeste. Aunque están representadas casi todas las zonas, la distribución de las excavaciones no es en modo alguno homogénea y así las áreas próximas a la costa atlántica están algo mejor representadas que las comarcas más interiores (fig. 1). El hecho de que gran parte de los materiales catalogados provenga de hallazgos casuales o excavaciones antiguas -en muchos casos habría que hablar más propiamente de remociones- introduce un elemento de incertidumbre en las conclusiones que podamos alcanzar respecto de la distribución y presencia de determinados artefactos, especialmente aquellos de menores dimensiones o poco atractivos a los ojos del coleccionista o aficionado.

Por último, a la hora de observar las asociaciones entre diversos útiles dentro de ciertos monumentos debe tomarse en consideración, además de las limitaciones antedichas, el carácter de panteón colectivo que éstos tendrían y, consecutivamente, el proceso de acumulación -a veces durante un periodo dilatado- de materiales representativos de etapas de utilización separadas en el tiempo ${ }^{4}$.

A efectos clasificatorios hemos agrupado el elenco de artefactos líticos recuperados en los megalitos del Noroeste en tres grandes apartados: "piedra pulimentada", "piedra tallada" y "otros". Mientras los dos primeros tienen una vigencia universal y una base tecnológica, la tercera categoría comprende una serie bastante heterogénea de objetos que comprende desde simples manuports hasta artefactos que han sufrido una leve transformación mediante piqueteado o a consecuencia del uso por parte del hombre. A su vez, cada uno de esos grandes grupos integra un número mayor o menor de tipos primarios (figs. 9-10) cuyas relaciones entre sí o con las diferentes estructuras tumulares han sido analizadas.

4 No obstante, es muy factible que en algunas de las construcciones más pequeñas y/ o antiguas el periodo de utilización fuese más limitado. Es posible incluso que algunos depósitos o sepulturas tumulares correspondan a un único momento: éste podria ser el caso, por ejemplo, de la mámoa núm. 3 de Pena Mosqueira, en Tras-os-Montes, (SANChes, M. J., "A mámoa 3 de Pena Mosqueira", Arqueologia, 15, 1987, págs. 94-115). 


\section{ASOCIACIONES ENTRE LOS MATERIALES LITICOS}

En el apartado anterior ya hemos glosado de forma abreviada algunas de las limitaciones con que se encuentra un trabajo llevado a cabo sobre yacimientos de la naturaleza de los megalíticos. A pesar de los condicionantes expuestos, la observación de las asociaciones existentes entre ciertos artefactos líticos puede ser valiosa cuando se detectan correlaciones fuertes entre elementos cuya cronología es total o parcialmente semejante o cuando éstos coinciden en sepulturas $u$ otros contextos cuya vigencia presumimos limitada ${ }^{5}$.

A la hora de examinar las frecuencias de asociación hay que tener en cuenta la mayor o menor presencia de unos y otros objetos. De esta forma una pauta simplemente media de aparición conjunta por parte de un artefacto que tenga una representación amplia debe considerarse más significativa que un coeficiente de aparición conjunta alto aplicado sobre un utensilio escasamente representado. Con la finalidad de simplificar la tabla anexa hemos excluido de ella aquellos elementos cuya aparición se limita a un solo yacimiento.

En una primera observación al cuadro adjunto (fig. 2) destaca el que sólo cinco tipos (por orden de importancia, hachas, lascas, puntas de flecha, hojas simples y elementos de molino) están presentes en más de un $25 \%$ de los yacimientos, mientras que los microlitos geométricos rozan dicho listón (23\%). Todavía habria que señalar un segundo grupo de objetos, representados en al menos un $10 \%$ del total de los megalitos estudiados (en orden decreciente, hojas retocadas, azuelas, guijarros, microhachas, cuentas, hojitas y prismas de cuarzo). En términos generales se puede intuir que entre los materiales mejor representados hay unos más "universales" - hachas, azuelas, microhachas, hojas y, en menor medida, puntas de flecha- y otros con tendencias asociativas más restringidas - microlitos geométricos, cuentas de collar, cinceles y, de forma menos significativa, molinos y lascas-. Los miembros de este segundo grupo tienen una cierta tendencia a comparecer junto a objetos de su mismo órbita morfotécnica: cinceles con artefactos de piedra pulida, microlitos con elementos de piedra tallada.

Dicha presunción podría aplicarse a la fosa excavada en el túmulo núm. 1 de Monte Campelos (Lugo). Rooriguez CASAL, A.-A., "A mámoa de Monte Campelos e o seu enterramento secundario. Novos datos encol do Megalitico Final galego", Boletin do Museo Provincial de Lugo, 1, 1983, págs. 7-17. 
Fig. 1. Relación de los túmulos catalogados en este trabajo: 1. -Túmulo 87 de Serra Faladora. 2.-Túmulo 81 de Serra Faladora. 3.-Túmulo 77 de Serra Faladora. 4.-Túmulo 245 de Veiga de Vilavella. 5.-Túmulo 229 de Veiga dos Mouros. 6.-Túmulo 219 de Veiga dos Muros. 7.-Túmulo 7 de Medoñas da Mourela. 8.-Túmulo de Monte das Arcas. 9.-Túmulo de Meirama. 10.-Dolmen de Dombate. 11.-Túmulo de Rechaba. 12. -Túmulo de Rabo de Lobo. 13. - Arca da Piosa (Pedra da Arca). 14.-A Mina de Parxubeira. 15.-Túmulo 3 de Parxubeira. 16. - Túmulo 4 de Parxubeira. 17.-Túmulo de A Martagona. 18. - A Cova da Moura. 19.-A Casota do Páramo. 20.-Dolmen de Axeitos. 21. - Túmulo 3 de Paradegua. 22. - A Mina de Burés. 23.-Túmulo 4 de Os Campiños. 24.-Túmulo 6 de Os Campiños. 25.-Túmulo 1 de Abelleira. 26.-Túmulo 2 de Abelleira. 27. - Túmulo 3 de Abelleira. 28. - Túmulo de Mariñaos. 29. -Túmulo de San Xoán de Alba. 30.-Túmulo 2 de Monte Pirleo. 31.-Túmulo 1 de Monte Campelos. 32. - Túmulo de Pago da Matela. 33.-Túmulo de Veiga das Mámoas. 34.-Túmulo de Penacabada. 35.-Túmulo 1 de Monte da Morá. 36. - Túmulo 7 de Monte da Morá. 37.-Túmulo de Tras as Casetas. 38.-Túmulo 1 de As Rozas. 39.-Túmulo de Campo da Anta. 40.-Túmulo 1 de Chan da Cruz. 41.-Mámoa do Rei. 42.-Túmulo 1 de Chan de Armada. 43.-Túmulo de Chan de Arquiña. 44. - Túmulo de As Pereiras. 45.-Túmulo de Monte da Esgueva. 46. -Túmulo 2 del km. 24 de la carretera Ribadavia-Cea. 47.-A Mota Grande de Monte Albán. 48. - A Mota Pequena de Monte Albán. 49.-Túmulo 7 de Lobeira. 50. - Lapa dos Mouros (dolmen da Barrosa). 51.-Cova dos Mouros. 52. - Antela do Maruco das Aguas. 53.-Antela 2 da Serra. 54.-Antela da Portelagem. 55.-Antela nos arredores de Sabroso. 56. - Túmulo del alto do Catorino. 57. - Túmulo 4 de Châ das Arcas. 58. -Túmulo das Carvalhas Alvas. 59. - Túmulo 4 da Presa. 60.-Dolmen A de Veiga de Perafita. 61.-Dolmen K de Veiga de Perafita. 62.-Anta da Estante. 63.-Anta da Burneira. 64.-Túmulo 1 de Madorras. 65.-Casa da Moura. 66. -Antela das Alminhas. 67.-Antela do Farilhe. 68.-Túmulo de Guilhabreu. 69.-Antela da Bouça dos Corgos. 70.-Túmulo de Arcos. 71.-Túmulo 4 de Meninas do Crasto. 72.-Túmulo 2 de Meninas do Crasto. 73. - Túmulo de Touta. 74. - Túmulo 3 de Châ de Parada. 75.-Mina do Simâo. 76. - Túmulo 1 de Cabritos. 77.-Túmulo 2 de Cabritos. 78. - Túmulo 1 de Abogalheira. 79. - Túmulo 1 de Outeiro de Ante. 80.-Túmulo 2 de Outeiro de Ante. 81. -Túmulo 3 de Outeiro de Ante. 82.-Túmulo 2 de Outeiro de Gregos. 83.-Túmulo 3 de Outeiro de Gregos. 84.-Túmulo 4 de Outeiro de Gregos. 85. - Túmulo 2 da Serrinha. 86. -Túmulo 1 de Châ de Santinhos. 87.-Túmulo 2 de Châ de Santinhos. 

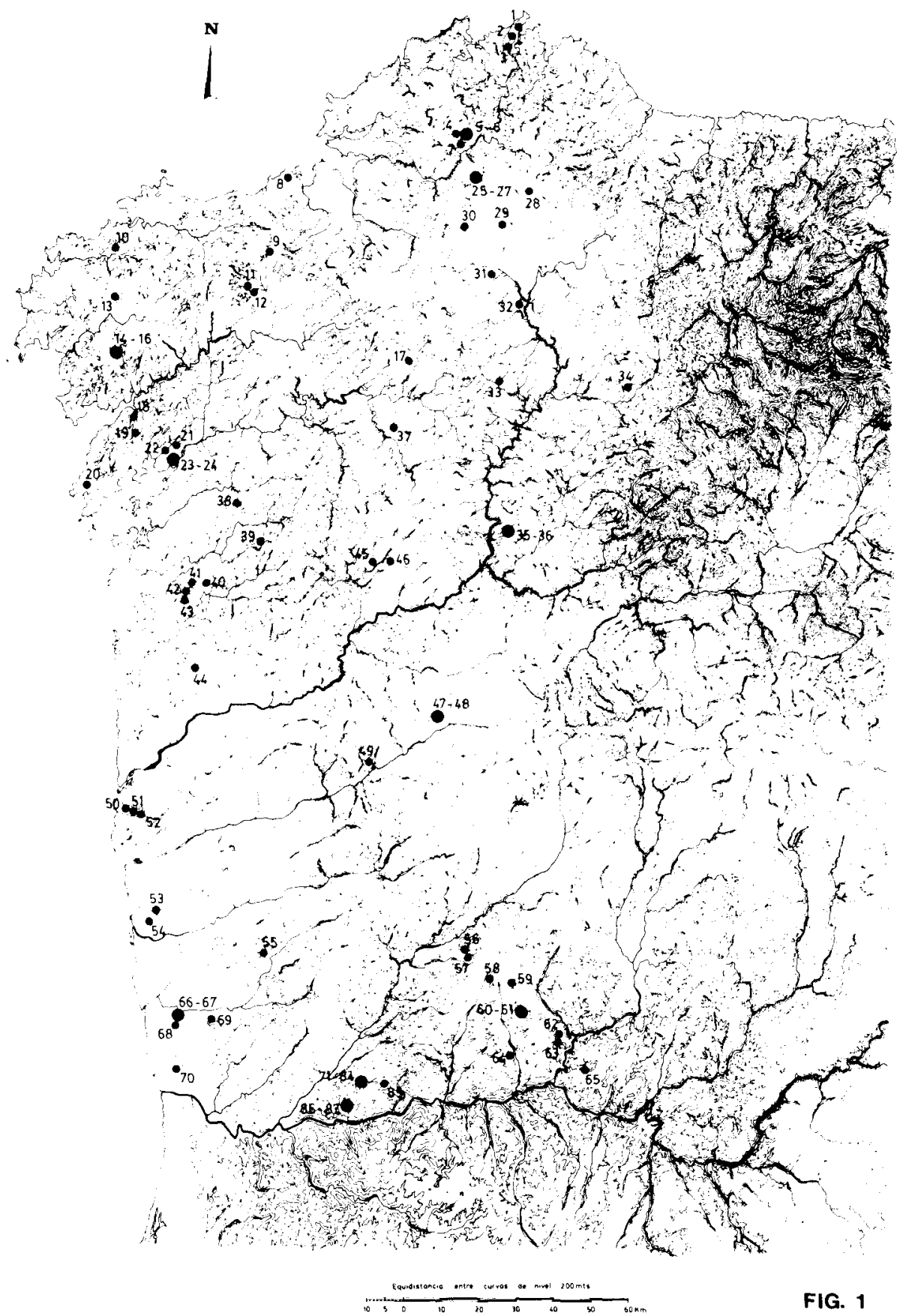

FIG. 1 
Algunas asociaciones bastante recurrentes pueden ser el reflejo, más - menos mediatizado por las violaciones y las dispares técnicas de excavación, de costumbres funerarias muy definidas para ciertos momentos o áreas dentro de la zona considerada. Éste podría ser el caso de la aparición conjunta de mazas, láminas de azada y/o cinceles, detectada en varios monumentos cuyas características arquitectónicas sugieren una utilización relativamente limitada en el tiempo. El conjunto microlitos geométricos/cuentas de collar/lascas/hojitas podría representar una tradición antigua dentro del ritual funerario que estuviese plasmándose en una parte de los megalitos del Noroeste. Esta coexistencia entre artefactos de piedra tallada de índole microlítica y elementos de adorno se encuentra documentada estratigráficamente en monumentos megalíticos - $\mathrm{O}$ niveles de éstos- de cronología arcaica como son Pena Mosqueira 3, Carapito 1 o El Miradero ${ }^{6}$. Ello no quiere decir obviamente que esta clase de materiales deba pertenecer siempre y en todo lugar a un horizonte antiguo del megalitismo. Por último, las notables pautas de asociación de puntas de flechas y hojas plantean un elenco de interpretaciones más abierto a discusión. Sin embargo cabría apuntar a título de hipótesis que la marcada correlación entre esos artefactos puede reflejar una parcial coetaneidad entre flechas y por lo menos una parte de las hojas -en especial las de mayores dimensiones-, que pasarian a integrar los ajuares megalíticos con cierta frecuencia en una etapa ya avanzada del fenómeno tumular, a mediados del III milenio, la cual vendría a coincidir asimismo con la generalización de las puntas de flecha como ofrenda funeraria en muchos monumentos.

\section{MATERIAL LITICO Y ESTRUCTURAS ARQUITECTÓNICAS}

Los dos elementos que integran un monumento megalítico, "túmulo" y "construcción interna" ${ }^{7}$, muestran una importante variabilidad, cada

${ }^{6}$ Sanches, "A mámoa..." citado; Delibes de Castro, G., Alonso Diez, M., y Galvan Morales, R., “El Miradero: Un enterramiento colectivo tardoneolitico de Villanueva de los Caballeros", Estudios en Homenaje al Dr. Antonio Beltrán Martinez, Zaragoza, 1986, págs. 227-236. Para el caso de Carapito 1 las interpretaciones efectuadas por $V$. Leisner en su momento se han visto confirmadas por la reciente reexcavación del yacimiento: Cruz, $D$. J., y VILACA, R., "Trabalhos de escavaçâo e restauro do dólmen 1 do Carapito", Trabalhos do Instituto de Antropologia, 45, 1990, pág. 12.

Recurrimos al circumloquio "construcción interna" en vez del termino más habitual, cámara, en razón de la existencia de túmulos que carecen de este recinto sensu stricto, presentando otro tipo de estructuras: pozos, lajas aisladas, etc. 
vez más patente a medida que se incrementa el número de excavaciones científicas. Sin embargo, tradicionalmente se ha mostrado escaso interés por el túmulo y las opciones que en el orden constructivo podía adoptar, como expresión de su relación dialéctica con otros componentes de la sepultura megalitica ${ }^{8}$. Por el contrario, la cámara o estructuras alternativas que se albergan en el interior del túmulo han centrado la atención de los investigadores por lo que su morfologia ha sido estudiada y sistematizada desde hace más tiempo, revelando un elenco tipológico bastante dispar, posiblemente como reflejo de la interacción de distintos factores, entre los cuales podrían citarse la cronología, la tradición y consideraciones de orden funcional o ritual.

En este apartado trataremos de detectar las posibles relaciones entre las distintas variedades arquitectónicas y el número o variedad de artefactos líticos recuperados en ellas. Dejando al margen el problema de la casi universal violación de los monumentos megalíticos a lo largo de los siglos, hay un factor especialmente distorsionante de nuestros resultados, representado por la distinta incidencia que en uno u otro tipo de monumento megalítico han tenido las exploraciones llevadas a cabo por aficionados. Ésta es máxima, como cabría esperar, entre las sepulturas indefinidas y rectangulares e importante en todas las demás, salvo las de corredor complejo. Las alteraciones producidas en la muestra analizada se acusan verosimilmente en mayor grado por lo que se refiere al número total de artefactos recuperados, especialmente debido a la pérdida de al menos una parte de los objetos de pequeño tamaño.

En lo referente a la tipología arquitectónica el trabajo más exhaustivo sigue siendo el de G. Leisner, sobre el que han abundado autores posteriores. Dicho autor encuadra las sepulturas megalíticas del Noroeste en tres grandes grupos: sepulcros de corredor, cámaras simples (ganglose Kammern) y hemidólmenes (Halbkammern) u otras estructuras a base de piedras aisladas. A esos tipos propiamente megalíticos añade más adelante los túmulos sin cámara ${ }^{9}$. Por nuestra parte, hemos procedido a ordenar los monumentos estudiados siguiendo en parte las pautas sentadas por Leisner, anadiendo algunas categorias de reciente definición en algún caso, mientras que otras son más bien un reflejo de las limitaciones de nuestro conocimiento actual (fig. 3).

${ }^{8}$ Sobre este aspecto puede verse especialmente: CrIADO BOAdO, F., «Megalitos, espacio, pensamiento". Trabajos de Prehistoria. 46, 1989, págs. 87-88; Criado BoAdo, F., y FABREGAS VALCARCE, R., "The megalithic phenomenon of NW Spain: main trends", Antiquity, 63, 1989, pág. 687.

${ }^{9}$ LEISNER, Verbreitung..., citado, págs. 18-32 y 44. 


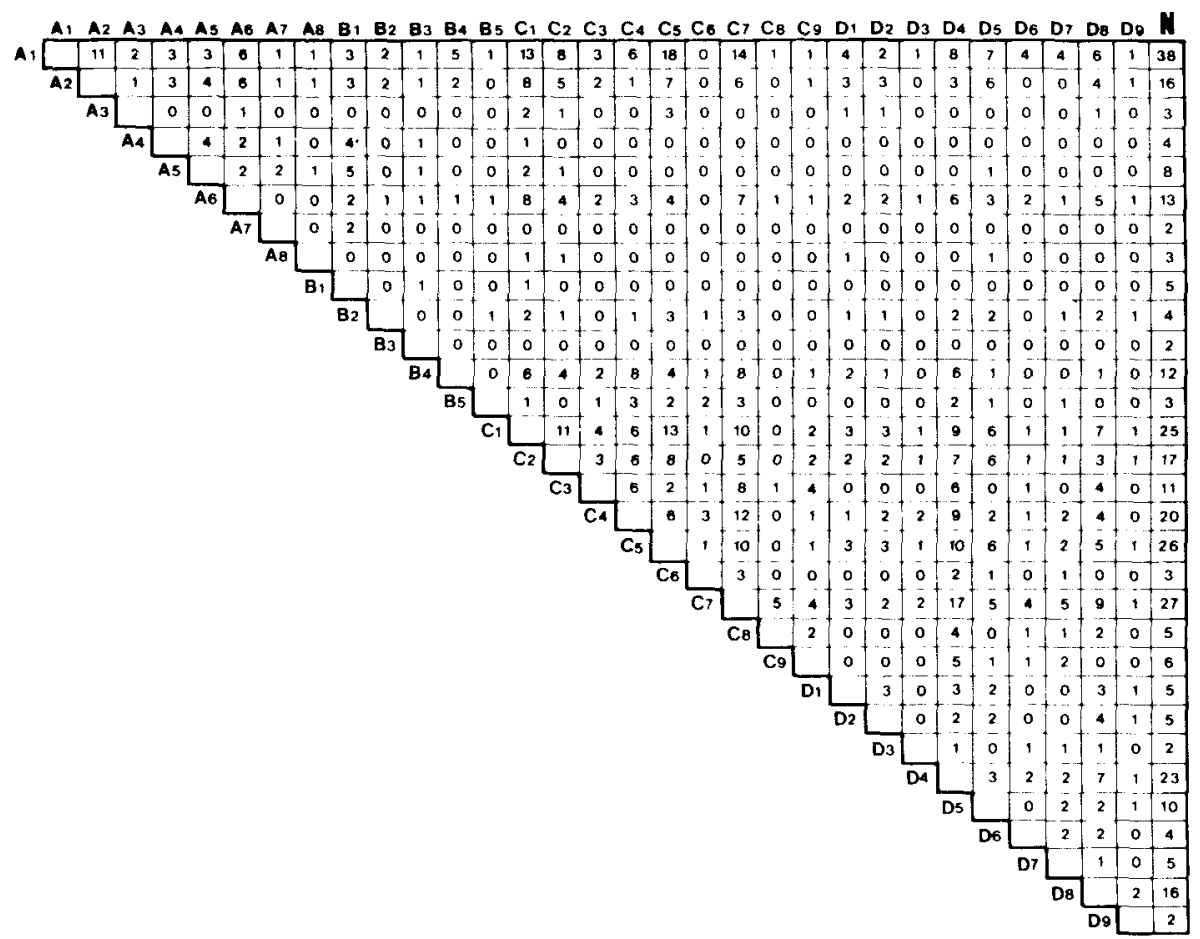

Fig. 2. Asociaciones de los artefactos líticos entre si. A1: Hachas; A2: Azuelas; A3: Gubias; A4: Láminas de azada; A5: Cinceles; A6: Microhachas; A7: Dobles azuelas; A8: Dobles hachas; B1: Mazas; B2: Bolas; B3: Discos Rechaba; B4: Cuentas; B5: Puntas de piedra pulida; $\mathrm{C1}$ : Hojas simples; C2: Hojas retocadas, C3: Hojitas; C4: Microlitos geométricos; C5: Puntas de flecha; C6: Núcleos; C7. Lascas; C8: Raspadores; C9: Percutores; D1: Idolos-guijarro; D2: Idolos tipo Argalo; D3: Betilos simples; D4: Molinos; D5: Prismas de cuarzo; D6: Piedras con cazoleta; D7: Discos; D8: Guijarros; D9: Pulidores; $N$ : número de yacimientos en los que aparece cada tipo de artefacto.

Sepulturas paramegaliticas (3). Hemos reservado este apartado para un pequeño número de monumentos, no necesariamente relacionados cultural o cronológicamente, que habiendo sido explorados con ciertas garantias, han proporcionado en el interior del túmulo estructuras distintas del habitual recinto ortostático, ya sean pozos o bien una simple laja enhiesta.

Cámaras rectangulares (7). Éstas constituyen recintos cerrados de planta más o menos semejante a dicha forma geométrica. Dentro de este 

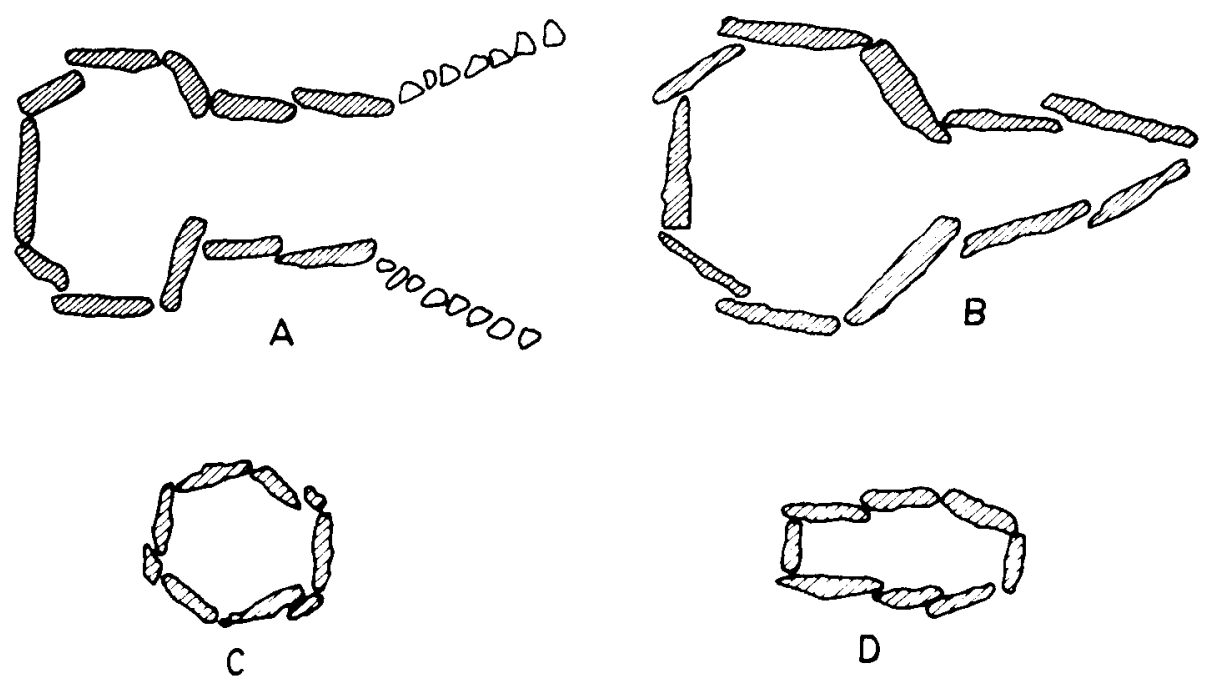

Fig. 3. Tipologia arquitectónica: A.-Sepulcro de corredor complejo (reconstrucción hipotética); B.-Sepulcro de corredor; C.-Cámara poligonal simple; D.-Cámara rectangular (cista). Se han usado diferentes escalas.

grupo, en general mal documentado arqueológicamente, habria que distinguir entre las "cistas", (fig. 3 d), presentes especialmente en el Norte de Galicia y caracterizadas por una tendencia hacia la reducción del espacio sepulcral, y las "antelas", localizadas preferentemente en el litoral de la región de Minho y de dimensiones algo mayores que las cistas.

Cámaras poligonales simples (17). También denominadas dólmenes simples, su planta se inscribe frecuentemente dentro de un heptágono o un octógono, pero pueden adoptar multitud de variantes: hexagonales, alargadas en el sentido axial o transversal, con o sin vano de entrada, etc. La dimensiones oscilan bastante, desde cámaras que no llegan a los $2 \mathrm{~m}$. hasta las que pasan de los $3 \mathrm{~m}$. en su eje mayor (fig. $3 \mathrm{c}$ ).

Cámaras poligonales indefinidas (17). Aquí incluimos las referencias antiguas, poco precisas, acerca de "dólmenes simples», o aquéllas más recientes sobre monumentos cuyo grado de deterioro sólo permitía aseverar, en función de los restos conservados, que se trataria probablemente de una cámara poligonal.

Sepulcros de corredor (19). Se caracterizan por poseer un pasillo que da acceso a la cámara propiamente dicha, el cual puede estar más 
- menos diferenciado de esta última en planta y/o alzado, pero que en todo caso no presenta normalmente más de dos ortostatos en cada lado. En este grupo se encuadran algunos de los mayores monumentos megalíticos de esta región, alcanzando en ciertos casos los $8 \mathrm{~m}$. de longitud para el conjunto cámara-corredor (fig. 3 b).

Sepulcros de corredor complejo (7). Bajo este epigrafe hemos reunido una serie de formas arquitectónicas detectadas en el curso de excavaciones recientes y que tienen como común denominador el énfasis puesto en las áreas de acceso al sepulcro, recurriendo para ello a diversas soluciones constructivas: prolongación del corredor ortostático mediante muretes de piedra seca y enlosados o "atrios" abiertos en el exterior del monumento. Es muy posible que con el estudio pormenorizado de nuevos megalitos de estas caracteristicas, se haga necesario el establecimiento de nuevos tipos en función de la morfología de las estructuras detectadas (fig. 3 a).

Sepulturas indefinidas (17). Habitualmente descubiertas o exploradas en tiempos antiguos, de ellas sólo tenemos vagas referencias acerca de la existencia de ortostatos, sin ulteriores precisiones. También se incluyen eventualmente algunos túmulos cuya estructura interna habia sido $\tan$ fuertemente alterada por las violaciones que era imposible identificarla con un mínimo de seguridad.

A la vista de la relación anterior destaca desafortunadamente la alta proporción de sepulcros indefinidos o poligonales indefinidos (38\% entre ambos). Por otra parte, la adscripción de ciertos monumentos a una categoría determinada no está exenta de incertidumbre, dada la limitada fiabilidad de las fuentes ${ }^{10}$. Así las cosas, creemos factible por ejemplo que dentro de los sepulcros de corredor haya monumentos de acceso complejo que sólo aguardan una buena excavación, mientras que en el grupo de sepulturas indefinidas puede hallarse con más probabilidad cámaras rectangulares, poligonales simples o paramegalíticas, en el caso de las dos primeras debido a sus frecuentemente modestas dimensiones que hacen más fácil la destrucción o el ser pasadas por alto, esto último muy posible en el caso de construcciones de tipo paramegalíiico, excavadas de forma descuidada.

${ }^{10}$ A fin de homogeneizar una muestra ya de sí muy heterogénea hemos excluido de los análisis de variedad o riqueza un total de siete yacimientos, en los que sólo se habia recuperado de forma accidental algún objeto aislado. 
Tipologia arquitectónica y número de artefactos liticos

Nuestra intención en el presente apartado es comprobar si existen diferencias significativas en cuanto a la cantidad de objetos líticos recobrados en los distintos tipos de monumento definidos más arriba. Para ello hemos procedido a calcular la media de artefactos dentro de cada grupo ${ }^{11}$ así como la correspondiente desviación tipica. La observación del cuadro adjunto permite aseverar la diferencia entre el valor hallado para los sepulcros de corredor complejo y los de todos los demás (fig. 4) aunque esta neta diferencia se atenúa a causa de las fuertes desviaciones típicas constatadas en todos los casos. A fin de contrastar las divergencias detectadas en un principio, hemos llevado a cabo un test de igualdad de medias para muestras pequeñas ${ }^{12}$, el cual nos ha permitido documentar que las diferencias señaladas en ningún caso alcanzan un nivel de significación suficiente ${ }^{13}$ si bien las existentes entre sepulturas de corredor complejo y cámaras poligonales simples por una parte, y entre las primeras y las cámaras rectangulares muestran un grado de significación bastante importante (90\% en ambos casos).

Una lectura rigurosa de los resultados del test de igualdad de medias nos induciria a concluir que no hay diferencias entre las distintas clases de sepulturas megalíticas en cuanto al número de artefactos líticos depositados en ellas. No obstante, creemos que con muestras menos afectadas por todo tipo de factores aleatorios (violaciones, deficientes excavaciones), algunos rasgos que despuntan con más fuerza (v. g. el

$"$ En el curso del recuento hemos procedido a multiplicar por un factor de 0,3 los valores correspondientes a lascas o restos de talla no conservados o documentados debidamente, los cuales por su gran número en algún monumento excavado hace años habrian alterado notablemente los resultados. Asimismo las referencias más o menos fiables acerca de "muchos" o "varios" ejemplares de un tipo de artefacto se han computado como 3.

12. Como paso previo se ha calculado si las varianzas poblacionales eran iguales, aceptando dicha hipotesis cuando el cociente de los cuadrados de las cuasivarianzas muestrales sea menor que el valor $\mathrm{Fa}, \mathrm{n}_{\mathrm{a}}-1, \mathrm{n}_{\mathrm{b}}-1$, proporcionado en una tabla de la distribución de Fisher-Snedecor. Tomaremos para el numerador la mayor de las desviaciones muestrales con el fin de realizar el test a una cola (Pena SAnchez, D., Estadistica. Modelos y métodos, Madrid, 1987, pág. 214). A continuación se lleva a cabo el contraste de hipótesis, siendo $H_{0}: \mu 1 \leqslant \mu 2$, aceptándose cuando el estadístico $T$ es menor que ta, $n_{1}+n_{2}-2$, valor que se encontrará en una tabla de la distribución t de Student (se tomará como media 1 la mayor de ambas) (VIzManos, J. R., y Asensio, R., Curso y ejercicios de bioestadistica, Madrid, 1976, págs. 22-223)

${ }_{13}$ Usualmente en los contrastes de hipótesis se toma el nivel del $95 \%$ como "casi significativo", el $99 \%$ como "significativo" y el 99,5 por 100 como "muy significativo" (VIzManos y Asensio, Curso.... citado, págs. 213). 
HE DE YHETOSOSEPULHUHA

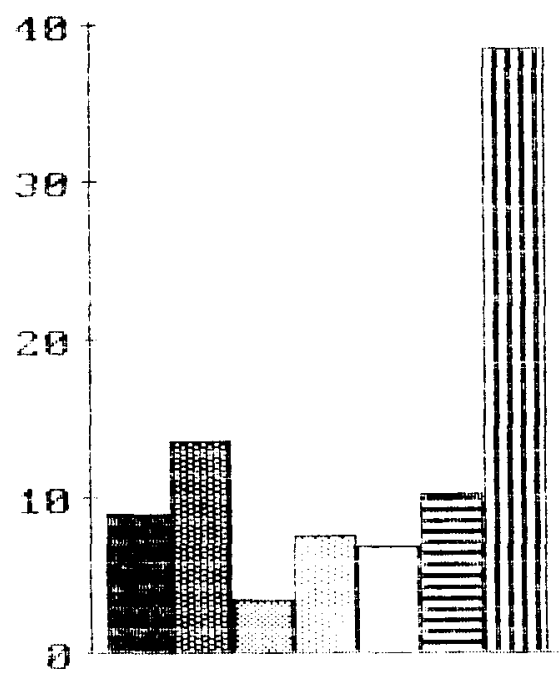

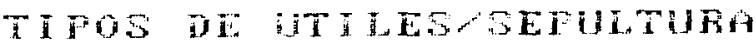
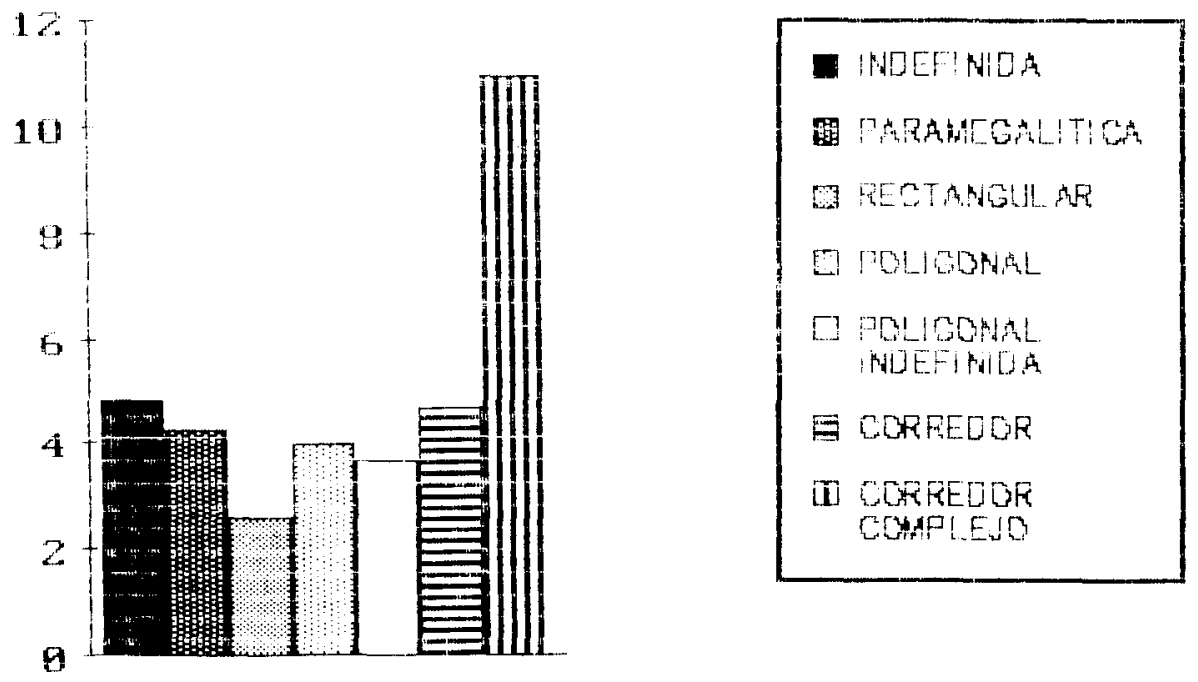

Fig. 4. Relación entre estructuras internas tumulares y riqueza o variedad del utillaje lítico. 
superior promedio de artefactos dentro de los sepulcros de corredor complejo) habrian quedado reafirmados.

No hay que olvidar, además, que el mayor o menor número de objetos depende de un número de factores intrínsecos al fenómeno megalítico mismo, interactuando o anulándose mutuamente: volumen útil de la cámara ortostática (cuando ésta existe) - lo que a su vez puede estar hasta cierto punto en relación con el carácter más o menos colectivo de la sepultura-, periodo de tiempo en que ésta fue utilizada, ritual funerario o disponibilidad de recursos. La diferente incidencia de estas $u$ otras variables en distintos momentos o regiones explicaría la heterogeneidad apreciable incluso dentro de un mismo grupo tipológico de monumentos megalíticos.

\section{NÚMERO DE ARTEFACTOS POR SEPULTURA}

\begin{tabular}{|c|c|c|}
\hline Tipo & Media & $\begin{array}{c}\text { Desviación } \\
\text { tipica }\end{array}$ \\
\hline Indefinidas (15) & 9,06 & 8,8 \\
\hline Paramegaliticas (3) & 13,6 & 11,37 \\
\hline Rectangulares (6). & 3,66 & 2,73 \\
\hline Poligonales (17). & 7,64 & 7 \\
\hline Poligonales indefinidas (17) & 6,88 & 5,1 \\
\hline Sepulcros de corredor (16) & 10,37 & 9,6 \\
\hline Corredor complejo (6) $\ldots \ldots \ldots \ldots \ldots \ldots$ & 38,6 & $3 \uparrow, 2$ \\
\hline
\end{tabular}

* Las cifras entre paréntesis indican el número considerado de monumentos de cada tipo.

Tipología arquitectónica y variedad artefactual

Hemos intentado comprobar la existencia de algún tipo de correlación entre la tipología de las sepulturas tumulares y el número de clases distintas de objetos líticos recobrados en ellas. Al igual que en el análisis anterior, hemos procedido en primer lugar al establecimiento del promedio de variabilidad para cada tipo de monumento, asi como la correspondiente desviación típica, para a continuación contrastar los valores obtenidos mediante un test de igualdad de medias para muestras pequeñas.

El cuadro adjunto proporciona una visión no muy diferente de la suministrada en el apartado anterior, destacando de nuevo el acentuado desmarque del grupo de sepulcros de corredor complejo (fig. 4). Sin em- 
bargo, el hecho de que las desviaciones típicas son más bajas en este caso, nos permitirá establecer diferencias entre ciertos tipos de monumentos. De esta forma, y por lo que se refiere a la variabilidad del material lítico, hemos hallado una divergencia importante entre las dos clases de sepulcros de corredor (nivel de significación del $99 \%$ ), así como entre los monumentos de corredor complejo, por un lado, y las cámaras poligonales simples o rectangulares, por el otro (en ambas comparaciones bajo un nivel de significación del $99 \%$ ).

NÚMERO DE TIPOS DE ARTEFACTOS POR SEPULTURA

\begin{tabular}{|c|c|c|}
\hline Tipo & Media & $\begin{array}{c}\text { Desviacion } \\
\text { tipica }\end{array}$ \\
\hline Indefinidas (15) & 4,86 & 4,01 \\
\hline Paramegalíticas (3) & 4,3 & 2,08 \\
\hline Rectangulares (6) & 2,66 & 1,36 \\
\hline Poligonales (17). & 4,05 & 2,27 \\
\hline Poligonales indefinidas (17) & 3,76 & 2,3 \\
\hline Sepulcros de corredor $(16) \ldots \ldots \ldots \ldots \ldots \ldots$ & 4,7 & 2,4 \\
\hline Corredor complejo $(6) \ldots \ldots \ldots \ldots \ldots \ldots \ldots \ldots$ & 11,16 & 4,79 \\
\hline
\end{tabular}

* Las cifras entre paréntesis indican el número considerado de monumentos de cada tipo.

La mayor diversidad respecto al utillaje lítico en las sepulturas de corredor complejo puede interpretarse en dos perpectivas, no necesariamente antagónicas: la de una utilización más prolongada en el tiempo, dadas las grandes dimensiones de la mayoría de estas construcciones ${ }^{14}$, y la de una mayor disponibilidad de recursos, complementada con el deseo de invertirlos en ceremonias funerarias de índole más elaborada, que pueden haber ido asociadas a la aparición de monumentos con estructuras complejas de acceso. La primera interpretación, muy verosimil, debe ser sin embargo sopesada a la luz de la escasa diferencia que en cuanto a variabilidad se constata entre los sepulcros de corredor y las cámaras poligonales simples, a pesar de que los primeros son por regla general de dimensiones superiores. Por su parte, el promedio de variedad tan claramente inferior en las camaras rectangulares puede estar

${ }^{14}$ Un ejemplo de utilización de la estructura interna de un sepulcro de corredor complejo a lo largo de medio milenio lo tenemos de Chá de Parada 1 (Baiâo, Oporto), como puede deducirse a través de las distintas dataciones radiocarbónicas obtenidas (JORGE, $V$. O., "Arqueologia social dos sepulcros megalíticos atlânticos: conhecimentos e perspectivas actuais". Revista da Faculdade de Letras, 6, 1989, pág. 397. 
motivado por tratarse - al menos una parte de ellas- de sepulturas de tamaño reducido, verosímilmente utilizadas en un lapso de tiempo muy limitado, aunque no hay que olvidar que la totalidad de los monumentos integrantes de este grupo fueron excavados antiguamente, por lo que la distorsión de nuestros datos puede ser máxima en el presente caso.

\section{Tipología litica versus arquitectura}

En este apartado compararemos las frecuencias absolutas de cada tipo de artefacto dentro de las distintas categorias arquitectónicas documentadas, a fin de ponderar la existencia de discontinuidades en la distribución de éstos 0 de relaciones entre determinados utensilios y estructuras constructivas ${ }^{15}$. A tal fin hemos elaborado un cuadro (fig. 5) en el que se plasman las frecuencias absolutas de aparición de los distintos útiles en cada una de las estructuras tumulares, y una segunda tabla (fig. 6) donde los artefactos son dispuestos en una secuencia numérica descendente. La observación de uno y otro cuadro permite la apreciación de divergencias bastante amplias en cuanto a la distribución

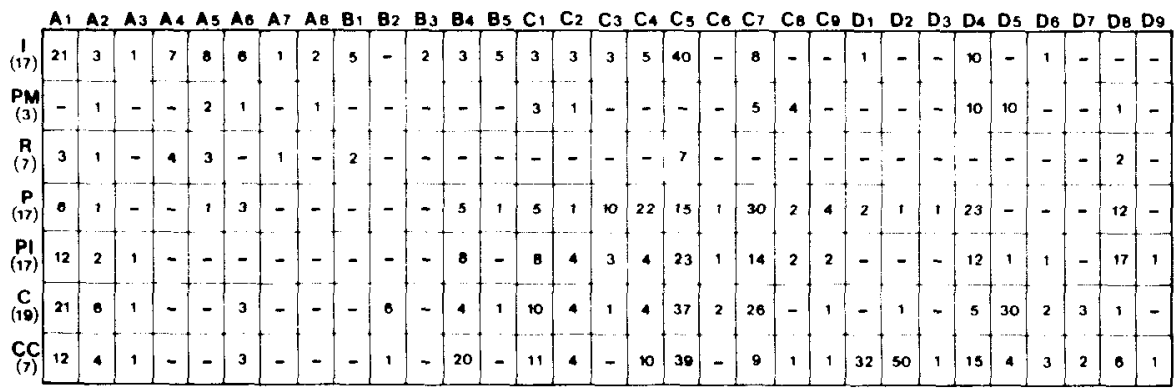

Fig. 5. Frecuencias absolutas de los artefactos líticos según el tipo de sepultura. A1: Hachas; A2: Azuelas; A3: Gubias; A4: Láminas de azada; A5: Cinceles; A6. Microhachas; A7: Dobles azuelas; A8: Dobles hachas; B1: Mazas; B2: Bolsas; B3: Discos Rechaba; B4: Cuentas; B5: Puntas de piedra pulida; C1: Hojas simples; C2: Hojas retocadas; C3: Hojitas; C4: Microlitos geométricos; C5: Puntas de flecha; C6: Núcleos; C7: Lascas; C8: Raspadores; C9: Percutores; D1: Ídolosguijarro, D2: Ídolos tipo Argalo; D3: Betilos simples; D4: Molinos; D5: Prismas de cuarzo; D6: Piedras con cazoleta; D7: Discos; D8: Guijarros; D9: Pulidores.

${ }^{15}$ En las tablas que a continuación se manejaran son considerados todos los munumentos, integrándose aquéllos previamente excluidos en los análisis de riqueza y variedad. 


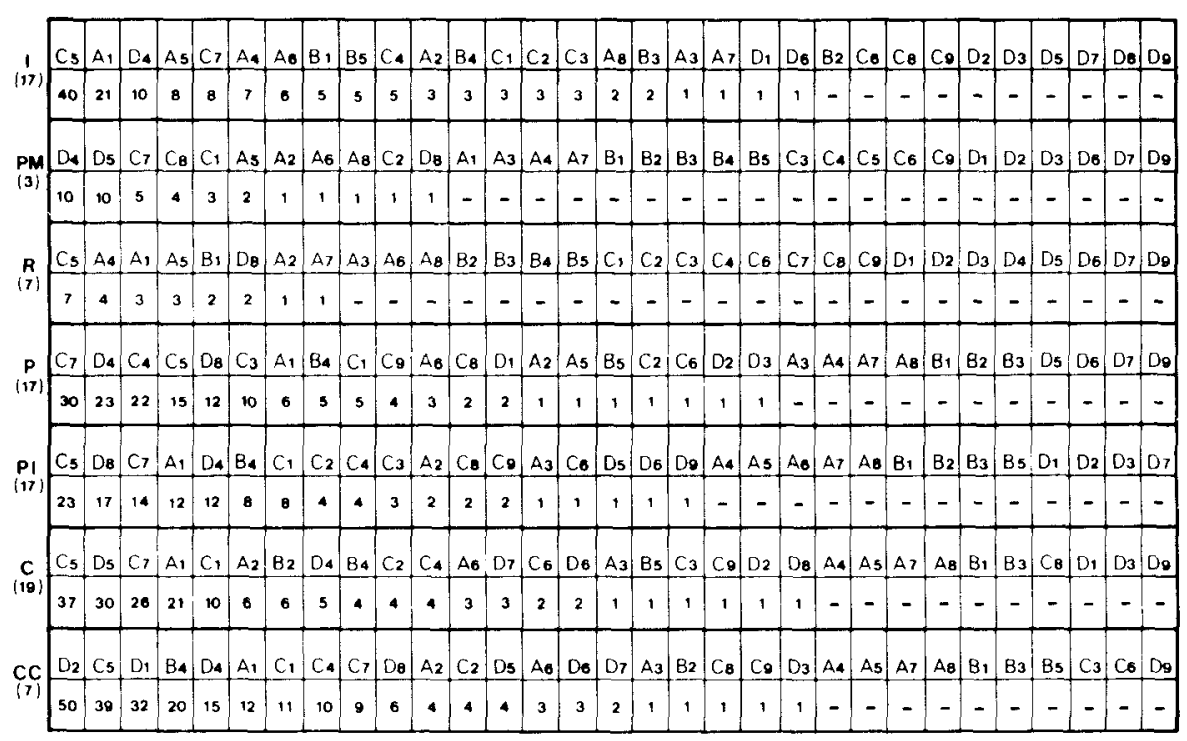

Fig. 6. Frecuencias absolutas de los artefactos líticos, ordenados en secuencia descendente, según el tipo de sepultura. A1: Hachas; A2: Azuelas; A3: Gubias; A4: Láminas de azada; A5: Cinceles; A6: Microhachas; A7: Dobles azuelas; A8: Dobles hachas; B1: Mazas; B2: Bolas; B3: Discos Rechaba; B4: Cuentas; B5: Puntas de piedra pulida; C1: Hojas simples; C2: Hojas retocadas; C3: Hojitas; C4: Microlitos geométricos; C5: Puntas de flecha; C6: Núcleos; C7: Lascas; C8: Raspadores; C9: Percutores; D1: Ídolos-guijarro; D2: Ídolos tipo Argalo; D3: Betilos simples; D4: Molinos; D5: Prismas de cuarzo; D6: Piedras con cazoleta; D7: Discos; D8: Guijarros; D9: Pulidores.

y frecuencia de determinados objetos, cuya significación hemos querido comprobar mediante la realización de varios análisis estadísticos.

En primer lugar se ha intentado establecer si para el conjunto de los monumentos estudiados existe una relación de dependencia significativa entre la tipología arquitectónica y la frecuencia de aparición de los distintos artefactos líticos, para lo cual se ha elaborado una tabla de contingencia total, calculándose a continuación el $X^{2}$ correspondiente ${ }^{16}$. El

16 Dado que algunas frecuencias son inferiores a 5 hemos recurrido a la corrección de Yates, que consiste en restar 0,5 a cada una de las diferencias entre las frecuencias observadas y las teóricas antes de elevar al cuadrado (VIZMANOS y ASENSIO, "Curso...", citado, pág. 255). 
resultado obtenido fue de $X^{2}=699.6778$ con 180 grados de libertad ${ }^{17}$, lo cual permite concluir que, en términos generales, existe dependencia entre el tipo de sepultura y los artefactos líticos depositados. A continuación se ha procedido a comparar de dos en dos las diferentes categorías arquitectónicas, evaluando las diferencias entre las frecuencias de cada par mediante un test del $X^{2}$. En todos los casos el $X^{2}$ resultante de las comparaciones ha sido superior al $X^{2} \alpha$ para un nivel de significación del $99,5 \%$, excepto en el contraste de las frecuencias correspondientes a las sepulturas indefinidas y rectangulares, en el que el nivel de significación es algo más bajo (95 por 100) ${ }^{18}$. En definitiva, los valores del $X^{2}$ hallados permiten afirmar con un grado importante de confianza que los diferentes tipos de sepultura considerados divergen significativamente entre si respecto a las frecuencias de los artefactos líticos recuperados en ellos ${ }^{19}$.

La observación de la secuencia ordinal en la figura 6 permite realizar varias aseveraciones: en primer lugar el hecho de que ningún tipo de útil se revela como dominante absoluto (poseyendo más de la mitad del total de los efectivos para un tipo arquitectónico determinado). Dentro del grupo de las "categorias mayores" (aquellos elementos cuya representación está por encima de la media) destacan puntas de flecha y hachas, que alcanzan ese rango en seis de las siete clases de sepultura, igual que acontece en cinco de éstas con hojas simples, molinos y lascas, mientras los microlitos geométricos son "categoría mayor» en cuatro variantes arquitectónicas, siéndolo en tres de éstas tan sólo guijarros, cinceles y cuentas. Un último aspecto a resaltar es la homogeneidad de conjunto que denotan las frecuencias de aparición de los útiles líticos en cada uno de los tipos de monumento considerados, ya que no hay en

17 Al ser la tabla $X^{2}$ válida hasta 30 grados de libertad, tenemos que calcular el estadístico $\vee 2 X^{2}-\sqrt{ } 2 n-1$, que sigue a una distribución normal de media 0 y desviación típica 1. El valor obtenido es 18,46 que siendo mayor que $X^{2} a$ para un nivel de significación del $99 \%$ permite rechazar la hipótesis nula "las variables consideradas son independientes entre sim.

${ }^{18} \mathrm{El}$ valor del $\mathrm{X}^{2}$ con 30 grados de libertad ha sido en casi todas las comparaciones efectuadas superior al del $X^{2} a$ bajo un nivel de significación del 99,5\% (53,7). En el caso del par sepulturas indefinidas-rectangulares el $X^{2}$ resultante $(44,7296)$ es inferior al $X^{2} a$ mencionado pero superior al $X^{2}$ a bajo un nivel de significación del $95 \%(43,8)$ lo que, al igual que en los casos anteriores, permite rechazar la hipotesis nula «las frecuencias del par analizado son homogéneas".

${ }_{19}$ Queremos agradecer a J. Valcarce Gómez, J. A. Berriochoa Esnaola y, muy especialmente, a E. Berriochoa Esnaola los consejos dados en el plano estadístico así como la realización de programas ad hoc que nos permitieron simplificar los de otro modo engorrosos cálculos. 
general grandes hiatos en el plano cuantitativo entre una clase de artefacto y la siguiente ${ }^{20}$.

Habiendo establecido más atrás la existencia de una dependencia significativa entre las frecuencias de aparición de los artefactos líticos en su conjunto y la clase de megalito de que se trate, procederemos ahora a examinar con más detalle la aparición o no de relaciones entre determinados utensilios (aquéllos con más entidad en términos cuantitativos) y ciertas variedades de sepultura. En cada instancia se establecerá la correspondiente tabla de contingencia a fin de contrastar la independencia de los caracteres analizados (un objeto determinado en relación con dos tipos de monumentos) ${ }^{21}$. Las principales observaciones deducibles a partir de los cálculos efectuados son las siguientes:

- Las puntas de flecha están presentes en todos los túmulos con estructura interna bien definida, con la excepción de los paramegalíticos. El análisis efectuado ha mostrado que su frecuencia de aparición es mayor en los sepulcros de cámara rectangular (antelas exclusivamente), seguidos en orden de importancia por los dos tipos de sepultura de corredor, pero sin que la diferencia entre los tres sea relevante a efectos estadísticos. Aunque las flechas aparecen asimismo en las cámaras poligonales, su presencia es significativamente menor que en los monumentos de cámara rectangular o de corredor ${ }^{22}$.

- Las hachas aparecen también en todos los túmulos con construcción interna bien definida, excepto los paramegalíticos. El análisis de las frecuencias absolutas indica que su presencia en los sepulcros de corredor es significativamente más abundante que en cámaras poligonales simples o monumentos de corredor complejo, pero no con respecto a las de planta rectangular ${ }^{23}$.

${ }^{20}$ Con algunas excepciones como la importante diferencia entre el número de flechas (C5), hachas (A1) y molinos (D4), respectivamente, dentro de las sepulturas indefinidas, 0 la discontinuidad existente entre los efectivos correspondientes a hachas (A1) y hojas simples (C1) en las sepulturas de corredor.

21 Se aceptará la hipótesis nula "la aparición de un objeto dado es independiente del tipo de sepulturas megaliticas comparadas", cuando el estadístico W calculado sea menor 0 igual que el valor de $X^{2}$ con 1 grado de libertad para un nivel de significación no menor del $95 \%$

${ }^{22}$ La divergencia entre las frecuencias correspondientes a cámaras poligonales simples y monumentos de corredor complejo es no significativa con reservas, ya que con un valor del $X^{2}=3,3$ la hipótesis nula sólo se rechaza bajo un nivel de significación del $90 \%$. Hay que tener en cuenta que la totalidad de las puntas de flecha halladas en las primeras proceden de un solo monumento (Parxubeira núm. 3).

${ }^{23}$ En el caso de las hachas, son las sepulturas indefinidas las que presentan la mayor frecuencia, aunque no significativamente superior a la correspondiente a las sepulturas de corredor. 
- Las hojas simples están ausentes de las sepulturas de planta rectangular, mientras que en el resto de las variantes arquitectónicas sus frecuencias de aparición no muestran diferencias significativas, aunque sean comparativamente más abundantes entre las construcciones paramegalíticas, seguidas por las dos clases de monumentos de corredor.

- Las piezas de molino están presentes con la mayor frecuencia en sepulturas paramegalíticas y poligonales simples, faltando por completo en las de cámara rectangular ${ }^{24}$. Si bien las diferencias entre las dos primeras carecen de relevancia, la divergencia de ambas con respecto a los dos tipos de monumentos de corredor es muy significativa ${ }^{25}$.

- Los microlitos geométricos, a pesar de constituir una categoria mayor en cuatro grupos arquitectónicos, muestran una acentuada heterogeneidad en sus frecuencias de aparición, pues son mucho más abundantes entre las sepulturas de cámara poligonal simple, siendo la diferencia por este concepto, entre éstas y el resto de los monumentos con estructura interna definida, muy significativa en todos los $\operatorname{casos}^{26}$.

- Las cuentas están completamente ausentes de los túmulos paramegalíticos o con cámara rectangular, pero tienen una cierta presencia en los sepulcros de corredor complejo ${ }^{27}$, algo superior a la correspondiente a sepulturas de corredor o con cámara poligonal simple aunque no respecto al grupo de poligonales indefinidas.

- Los guijarros, que se configuran como una categoría mayor en tres clases de sepultura (de cámara rectangular, poligonal simple y poligonal indefinida), no muestran entre ellas diferencias significativas en cuanto a su frecuencia. Con relación a las demás categorías arquitectónicas, únicamente puede apuntarse que los guijarros son más abundantes en túmulos con cámara poligonal indefinida o simple que en los monumentos de corredor y paramegalíticos.

24 En relación con la presencia o ausencia de ciertos artefactos, como lascas o molinos, debe tenerse muy en cuenta que la totalidad de las sepulturas con cámara rectangular estudiadas han sido excavadas antiguamente.

25 En todas las comparaciones realizadas, el valor del $X^{2}$ resultante conlleva rechazar bajo un nivel de significación del $99,5 \%$ la hipótesis nula, lo que en el caso presente permite aseverar que las dos clases de sepulcros de corredor son relativamente más pobres en elementos de molino que los monumentos paramegalíticos o de cámara poligonal.

26 Las comparaciones efectuadas permiten rechazar en cada instancia la hipótesis nula para un nivel de significación del $99,5 \%$.

${ }_{27}$ Debe tenerse muy en cuenta, no obstante, que las tres cuartas partes de los efectivos provienen de un solo monumento (Madorras 1). 
- Los cinceles denotan una distribución francamente sesgada pues sólo aparecen en cuatro grupos arquitectónicos, constituyendo en tres de ellos (sepulturas indefinidas, paramegalíticas y con cámara rectangular) una categoría mayor, mientras en el cuarto (poligonales simples) tienen una presencia puramente testimonial. Los tres grupos aludidos en primer lugar no muestran diferencias significativas respecto a la frecuencia de aparición de dichos utensilios.

Entre los artefactos con una distribución más restringida debemos señalar las láminas de azada y las mazas, que son categorias mayores -y aparecen exclusivamente- en los mismos tipos de monumentos (sepulturas indefinidas y con cámara rectangular), no habiendo diferencias relevantes en cuanto a las frecuencias respectivas en el caso de las mazas, mientras que las láminas de azada son significativamente más abundantes en las sepulturas con cámara rectangular. Los prismas de cuarzo constituyen una categoría mayor dentro de las sepulturas paramegalíticas y de corredor, sin que exista una divergencia relevante en sus frecuencias respectivas, pero si entre cualquiera de ellas y las del resto de los monumentos con esa clase de objetos. Las hojitas están presentes en cuatro de los tipos de estructura arquitectónica definidos, pero sólo alcanzan el rango de categoría mayor dentro de las cámaras poligonales, aunque de todos modos no existe diferencia significativa con la frecuencia correspondiente a las cámaras poligonales indefinidas y tampoco - con más reservas- respecto a las indefinidas ${ }^{28}$, pero sí en relación a las de corredor. Por último, los idolos-guijarro y de tipo Argalo sólo se configuran como una categoría mayor dentro de los sepulcros de corredor complejo, siendo su presencia en otros tipos de monumentos testimonial y, desde luego, significativamente inferior.

Las comparaciones efectuadas en las páginas precedentes están en determinados casos inevitablemente lastradas por la parquedad de efectivos que afecta a alguna de las categorias arquitectónicas, en particular la de las sepulturas paramegalíticas. Por otra parte, éstas y las de cámara rectangular especialmente engloban monumentos que responden con probabilidad a tradiciones culturales dispares, a veces asincrónicas. Estos factores deben ser tenidos en cuenta a la hora de valorar la magnitud de las diferencias detectadas en las frecuencias de aparicion de los diversos artefactos líticos. A partir de los resultados expuestos en

${ }^{28}$ En la comparación entre las frecuencias de cámaras indefinidas y poligonales el $X^{2}$ obtenido $(3,55)$ se aproxima mucho al correspondiente a un nivel de significación del $95 \%$ $(3,84)$. 
las páginas anteriores y de la simple observación de las figuras anexas (figs. 7 y 8 ) pueden extraerse algunas conclusiones provisionales en relación con aquellos túmulos dotados de una construcción interna bien conocida:

- Los túmulos paramegalíticos poseen una abundancia especialmente significativa de molinos, lascas, prismas de cuarzo, raspadores y cinceles. Su pequeño número limita sin embargo el valor de los análisis realizados.

- Los túmulos con cámara rectangular registran con más frecuencia la aparición de hachas, puntas de flecha, guijarros, cinceles, mazas, láminas de azada, dobles azuelas y mazas. Dentro de este grupo, por to demás muy reducido numéricamente ${ }^{29}$, existe un nítido deslinde entre las antelas de la región de Minho y las cistas del Norte de Galicia, correspondiendo a las primeras las flechas en exclusiva y a las segundas el resto de los materiales.

- Las sepulturas con cámara poligonal simple se señalan por la mayor presencia de microlitos, molinos, lascas, guijarros y, de forma no tan significativa, hojitas.

- Los sepulcros de corredor tienen un número particularmente grande de flechas, lascas, prismas de cuarzo, hachas, bolas y discos.

- Los sepulcros de corredor complejo se distinguen especialmente por la presencia de idolos-guijarro, de tipo Argalo, cuentas de collar y - con menor significación- puntas de flecha. Desgraciadamente este grupo tiene una representación númerica más reducida de lo que seria deseable.

\section{INDUSTRIA LITICA: DISTRIBUCIONN ESPACIAL}

Tradicionalmente se ha contemplado el fenómeno megalítico del Noroeste peninsular en términos genéricos, asumiendo explícita o implicitamente que éste constituia un ente unitario. Con esta perspectiva se planteaba la ordenación cronológica relativa de las distintas formas sepulcrales tumulares como si ésta fuese unilinear e idéntica en todos los lugares.

$29 \quad Y$ con el problema adicional, ya mencionado con anterioridad, de que todos los monumentos han sido explorados en epoca antigua. 


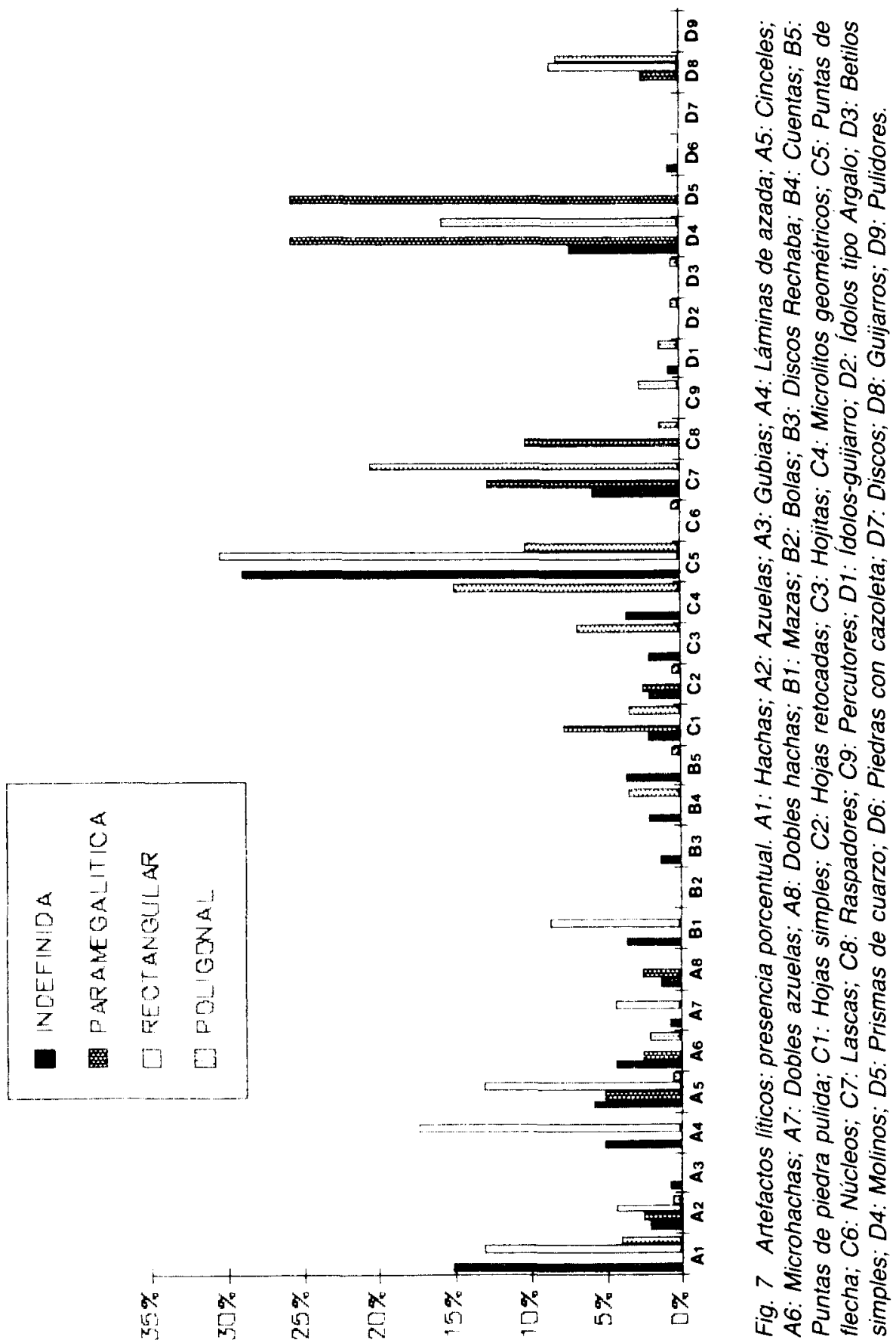




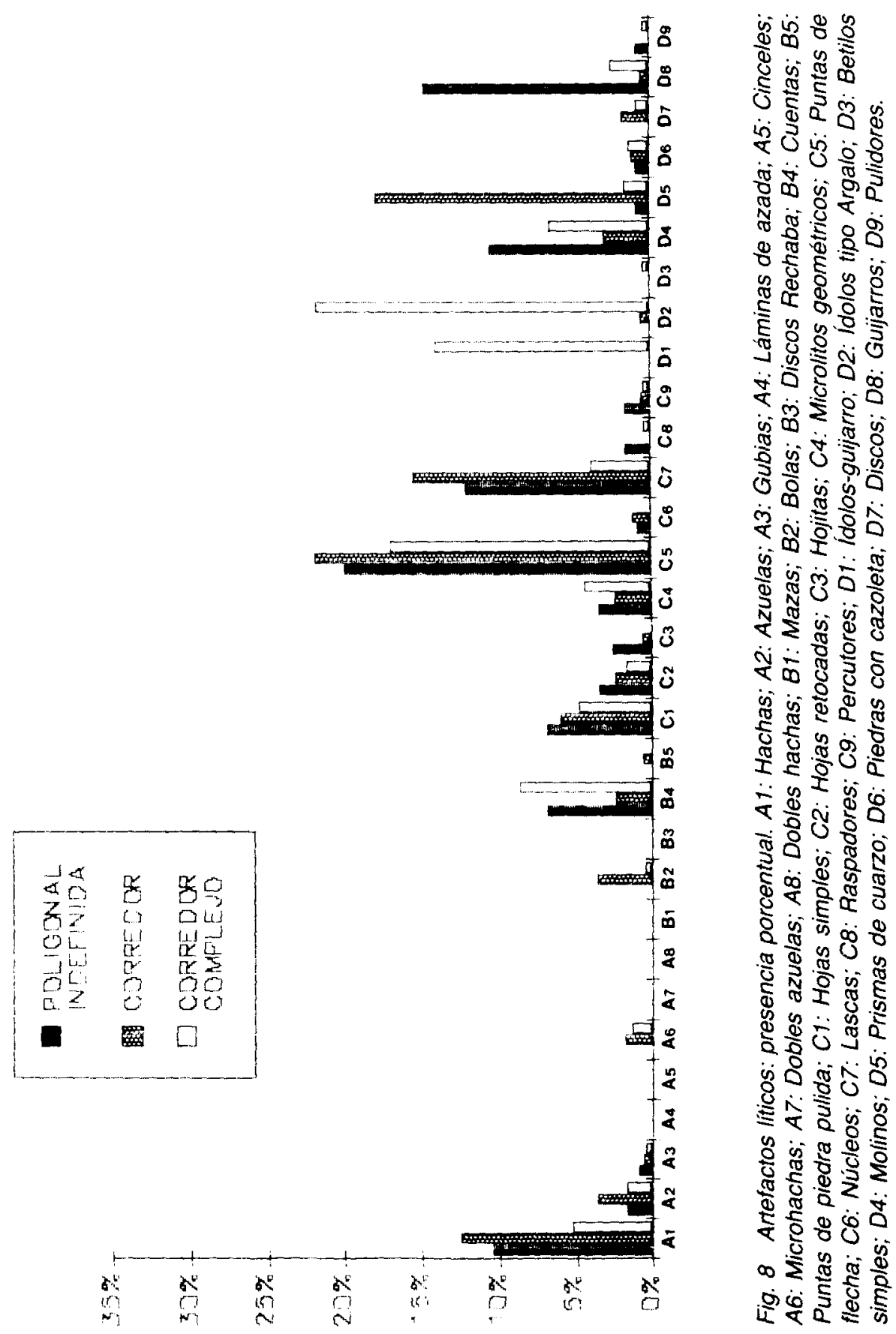


Esta visión excesivamente esquemática era hija de unas circunstancias muy concretas en cuanto al nivel de conocimiento arqueológico de esta área peninsular: las excavaciones metódicas eran casi inexistentes y el conocimiento de las necrópolis tumulares sólo parcial, a través de exploraciones efectuadas al azar, sin un criterio bien definido y consecuente. Esta tónica ha cambiado en los últimos años, al compás del aumento en el número de excavaciones científicas y la subsiguiente obtención de un buen número de dataciones absolutas que, si bien confirmaban parcialmente algunas de las ideas tradicionales, por otro lado ponian en evidencia el polimorfismo de los túmulos megalíticos y la sincronia, al menos parcial, de diversas fórmulas arquitectónicas, fenómenos éstos que pueden estar relacionados con circunstancias económicas y sociales particulares de determinadas áreas dentro del Noroeste, las cuales comienzan a aflorar tímidamente a medida que progresa la investigación.

Nuestra pretensión de detectar alguna clase de tendencia regional por lo que al material lítico se refiere, tropieza con el obstáculo representado por la falta de homogeneidad de la muestra en cuanto a su distribución territorial. En efecto, disponemos de un importante núcleo de yacimientos (18) en torno a las Rias Bajas y litoral occidental galaico, otra concentración de menor entidad en la orla costera de las regiones portuguesas de Minho y Douro Litoral (11 monumentos), más al interior el area intensamente excavada de Aboboreira con 16 túmulos y por último otros 12 yacimientos en la cabecera del valle del Miño y alto Eume. Aun teniendo en mente los resultados de excavaciones recientes efectuadas en Tras-os-Montes ${ }^{30}$ o en la Galicia central ${ }^{31}$, éstas y otras regiones interiores están claramente subrepresentadas en nuestro estudio. Otro problema, al que ya aludimos al comienzo de este trabajo, es el de la disparidad de las técnicas aplicadas a la recuperación de los objetos analizados, lo cual nos obliga a ser extraordinariamente prudentes a la hora de evaluar, por ejemplo, la ausencia de determinados artefactos en ciertas zonas con pocas o ninguna excavación efectuada con metodología moderna.

\section{Localización espacial}

En una primera aproximación podriamos dividir los materiales estudiados más significativos en varias categorias, a tenor de su número y

\footnotetext{
3o Pena Mosqueira y Mamoa do Barreiro, ambos en el distrito de Bragança.

31 Como parte del proyecto arqueológico de Serra do Bocelo (Melide, Coruña) se han excavado tres túmulos.
} 
área de aparición. De esta forma tendriamos entre los objetos escasos algunos con una distribución muy delimitada y otros más ubicuos; en el caso de los materiales que se presentan con cierta abundancia es posible tomar en consideración nuevas variables como pueden ser la abundancia o el tamaño en relación con la localización geográfica.

Hay un grupo de objetos líticos con poca representación numérica pero que no obstante se documentan en puntos muy alejados entre si: gubias, piedras con cazoleta, raspadores y cantos tallados. Salvo las gubias - un utensilio raro en todas partes-, el resto de los artefactos tienen en común su escaso atractivo estético o patrimonial, lo cual nos lleva a pensar que los vacios que hoy se denotan en su distribución podrian llenarse al menos en parte con la realización de más excavaciones científicas ${ }^{32}$.

Mayor potencial de información puede obtenerse de aquellos objetos que siendo númericamente escasos muestran además una localización restringida. En función de esta última podemos distinguir un grupo de materiales que se encuentra fundamentalmente en las penichairas surcadas por el curso superior del Miño, con una ampliación hacia el Norte en el alto Eume y hacia el Oeste por las cabeceras de los rios Tambre y Ulla. En esta zona se encuentran la casi totalidad de los hallazgos documentados de mazas, dobles hachas, discos perforados y Rechaba, cinceles, dobles azuelas y láminas de azada. Otro grupo más reducido de objetos líticos (bolas y puntas de piedra pulida) aparece básica o exclusivamente en el cuadrante suroccidental de Galicia, entre el rio Tambre y el bajo Miño.

Hay artefactos que a pesar de su relativa abundancia parecen presentar una difusión muy limitada, como en el caso de las hojitas que fuera de la sierra de Aboboreira sólo aparecen en lugares aislados. Sin embargo, creemos que estas piezas pueden haber sido fácilmente pasadas por alto en excavaciones antiguas, dado su pequeño tamaño y poco vistosas características, por to que cabe esperar un aumento de hallazgos en el futuro que vengan a colmar en parte los vacios actualmente existentes en su distribución ${ }^{33}$. Por otra parte, esa localización

32 A título ilustrativo podemos mencionar el caso de los cantos tallados, de cuya presencia sólo se tenia noticia en un túmulo (núm. 77) de Serra Faladora (Norte de Coruña), hasta fechas recientes en que se han documentado nuevos hallazgos de esta clase en dos megalitos de Aboboreira (Châ de Parada 1 y Monte da Olheira) y en la Mamoa da Eireira (Viana do Castelo).

33 En monumentos excavados recientemente como el de Forno dos Mouros (Melide, Coruña) ha aparecido varias hojitas. 
tan reducida debe responder hasta cierto punto a una menor presencia real de esos elementos en contextos megalíticos pues otros utensilios (v. g. microlitos), a despecho de su escaso tamaño, están presentes en un número de yacimientos bastante más extenso.

Las puntas de flecha tienen en conjunto una presencia numérica fuerte y su aparición se documenta en casi todas las zonas del Noroeste. Con todo, bajo esta homogeneidad aparente pueden detectarse algunas tendencias particulares, fundamentalmente en lo que se refiere a la riqueza en este tipo de materiales dentro de los distintos yacimientos megalíticos. En este aspecto se aprecia una clara dicotomía entre los túmulos situados en el litoral o en su entorno próximo y aquéllos sitos en el interior, de forma que todos los monumentos con cinco o más puntas de flecha se localizan en la orla costera, salvo uno (Châ de Parada 1), excavado recientemente en la sierra de Aboboreira ${ }^{34}$. Al ser estas piezas relativamente grandes y ciertamente llamativas, no creemos que la metodología de excavación pueda explicar por sí misma una divergencia tan absoluta, pues incluso un buen número de trabajos arqueológicos efectuados de forma cuidadosa en Galicia central o Tras-os-Montes han evidenciado la ausencia de esta clase de utensilios ${ }^{35}$, mientras, por el contrario, varios de los importantes hallazgos costeros provienen de exploraciones antiguas.

Los objetos cultuales con mayor representación numérica (ídolos-guijarro y tipo Argalo) presentan una distribución aún más delimitada que las puntas de flecha, pues se ciñen casi exclusivamente a yacimientos gallegos próximos a la costa, mientras en las tierras interiores sólo comparecen de forma aislada otros tipos de idolos. Es cierto que la simplicidad de muchos de los objetos cultuales considerados y su localización preferente en el exterior de los corredores ha influido probablemente en la poco frecuente detección de estas piezas, pero de todos modos es significativo que en excavaciones rigurosas efectuadas últimamente en áreas interiores (Aboboreira, Tras-os-Montes) o en la costa de Minho, los hallazgos de idolos-guijarro o tipo Argalo han sido prácticamente nulos.

${ }^{34}$ Unico monumento entre los más de veinte ya excavados en este gran núcleo megalítico que ha suministrado un cierto número de puntas de flecha (5) (JORGE, V.O., y Bettencourt, A. M. S., "Sondagens arqueológicas na mamoa 1 de Chá de Parada", Arqueología, 17, 1988, págs. 73-118). Otros dos ejemplares fueron recogidos aisladamente en sendos túmulos de esta misma zona (Serrinha 2 y mamoa do Outeiro).

${ }^{35}$ Este es el caso de los tres sepulcros de Abelleira, Forno dos Mouros o Madorras 1 , por ejemplo. 
Existe una serie de artefactos cuantitativamente importantes y que además están distribuidos de una forma más o menos homogénea a lo largo y ancho del Noroeste. Los principales entre ellos son las hachas, microhachas, molinos, azuelas, hojas retocadas, lascas y guijarros. A este mismo grupo podemos adscribir algunos objetos que, manteniendo las características mencionadas, presentan algunos rasgos peculiares si correlacionamos la ubicación espacial con aspectos morfológicos o tipológico. Este sería el caso de las hojas simples, cuyos ejemplares de mayor tamaño (anchura $>20 \mathrm{~mm}$ ) se concentran preferentemente en el área próxima al litoral (siete de los 10 yacimientos con ese modulo de hojas), donde además los ajuares suelen ser más ricos en dicha clase de utensilios ${ }^{36}$. Por su parte, los microlitos geométricos muestran también una distribución relativamente homogénea en el territorio objeto de estudio, caracteristica que se quiebra claramente cuando entran en liza consideraciones de orden tipológico, pues en este aspecto parece existir una divergencia entre las zonas gallega y portuguesa, documentándose en la primera sólo trapecios, mientras que en el Norte de Portugal aparecen junto a éstos - aunque de forma minoritaria - triángulos y segmentos.

Localización espacial y cronologia

Haciendo abstracción de variables como la metodologia de excavación o las violaciones sufridas por las sepulturas, las características de los ajuares líticos procedentes de éstas son una consecuencia de la intervención de varios factores: rituales, económicos y cronológicos. Este carácter polifacético dificulta la definición de tendencias regionales dentro del mundo megalítico del Noroeste, pues nuestro conocimiento es todavia limitado por 10 que se refiere a los aspectos rituales o económicos y desigual en cuanto a la cronologia. Por todo ello las ideas que vamos a exponer a continuación tienen una fuerte componente hipotética y gene-

${ }^{36}$ Excavaciones recientes en túmulos de la zona costera no hacen más que reforzar esta tendencia, como es el caso - entre otros - de la Mamoa da Eireira (Viana do Castelo), donde se recuperaron cinco hojas simples, una de ellas al menos de grandes dimensiones (SiLva. E. J. L. da, "A Mamoa de Afife: breve sintese de 3 campanhas de escavaçâo". Trabalhos de Antropologia e Etnologia, 28, 1988, págs. 127-132). 

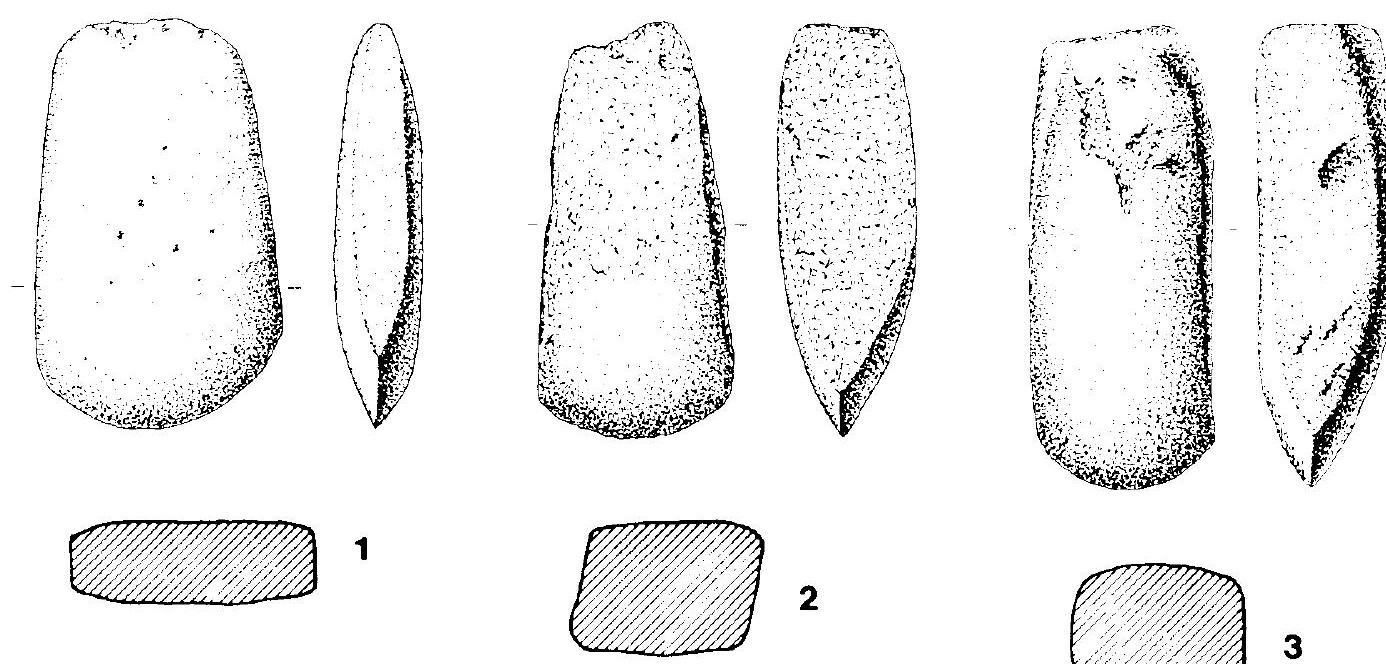

2

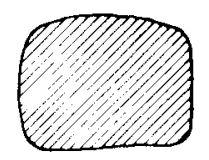

3
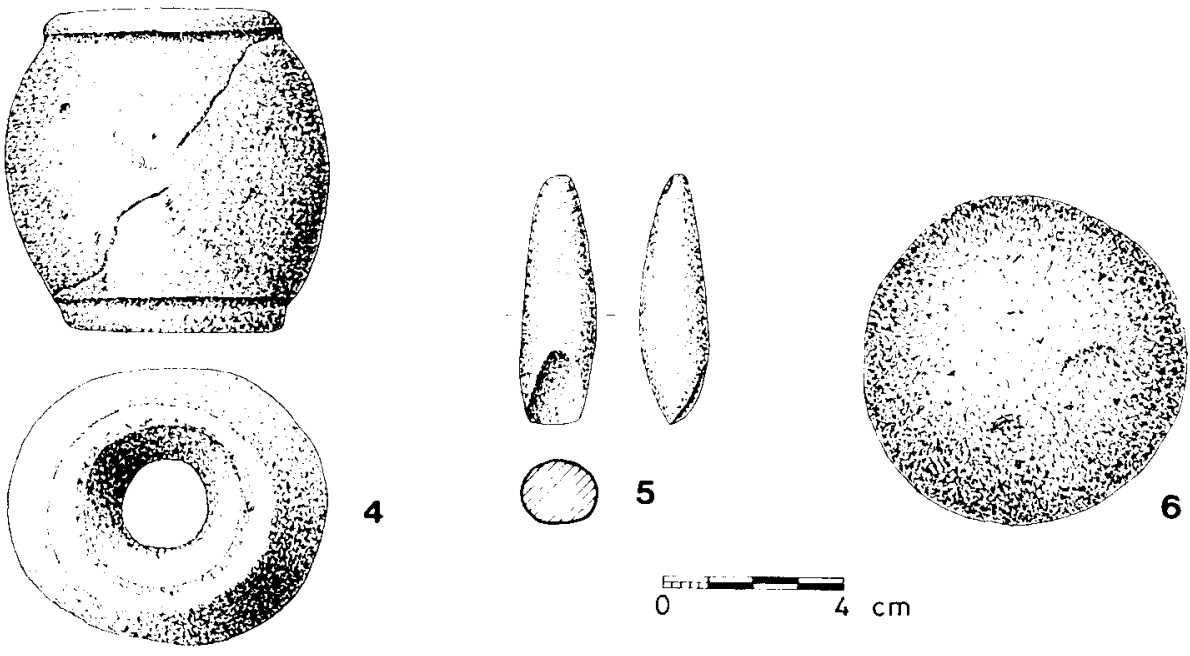

Fig. 9. Objetos líticos característicos: 1. Hacha tipo II; 2. Hacha tipo I; 3. Azuela tipo I; 4. Maza; 5. Microhacha; 6. Bola. 

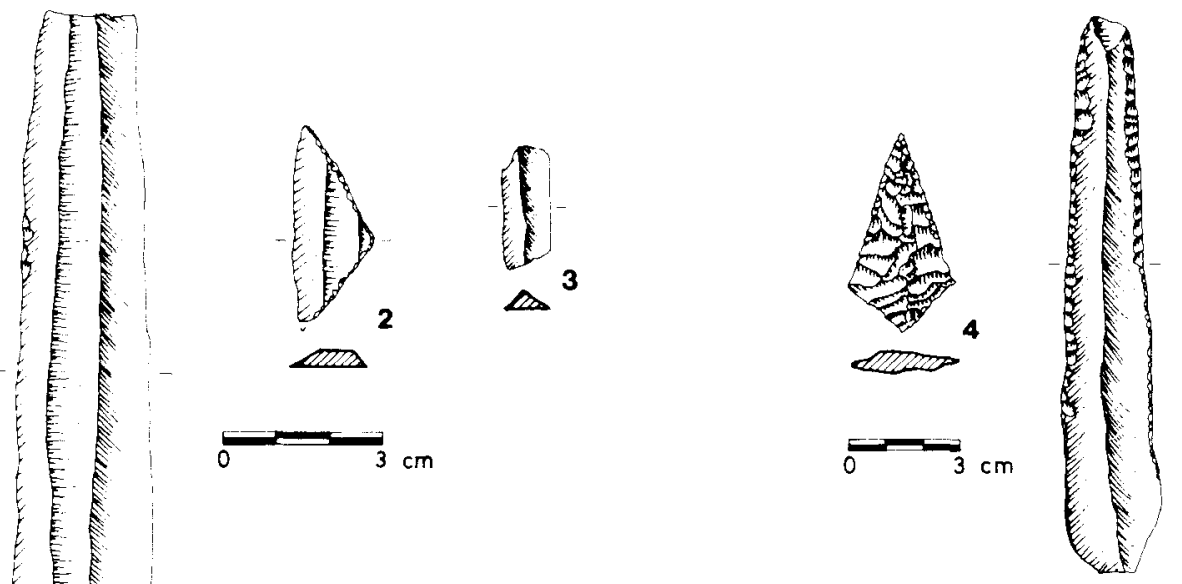

5
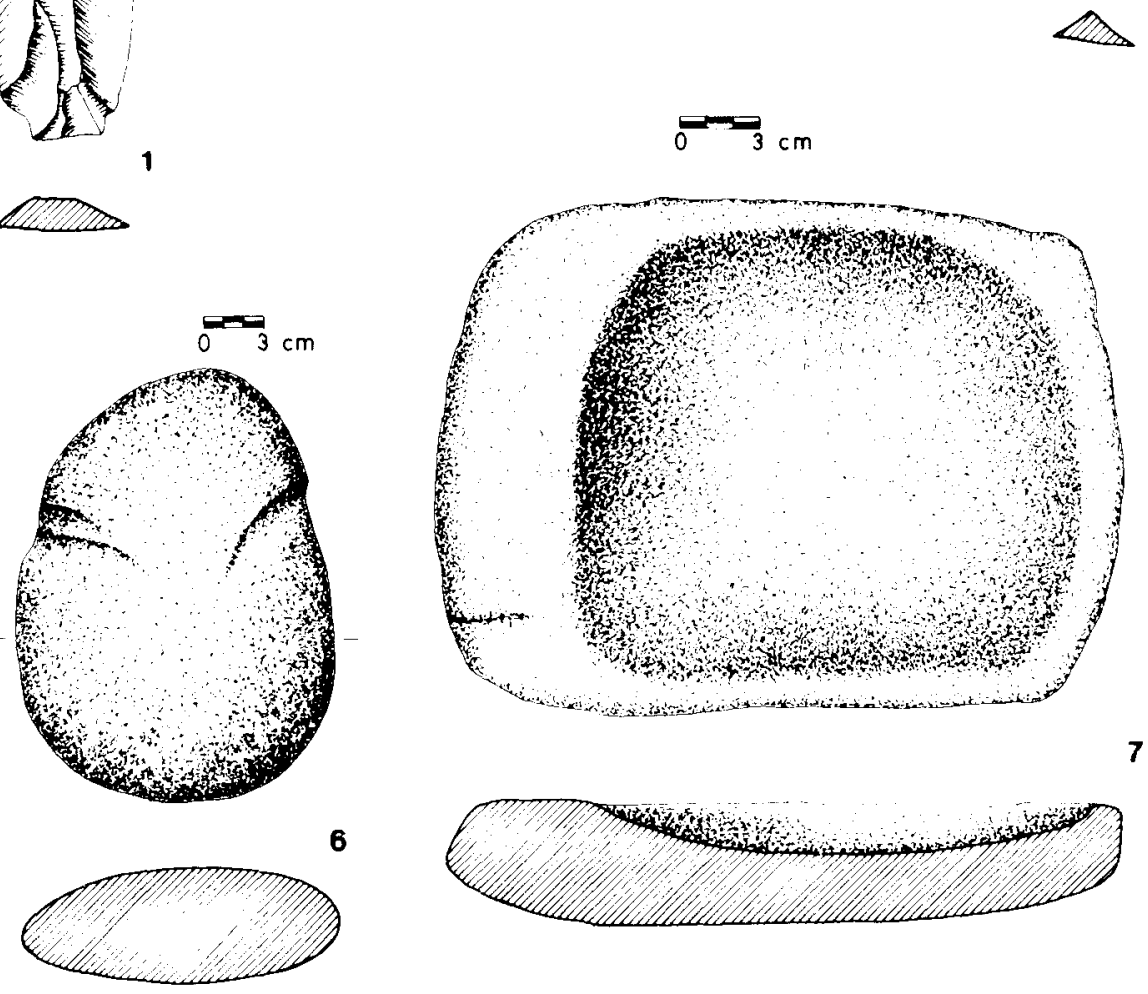

7

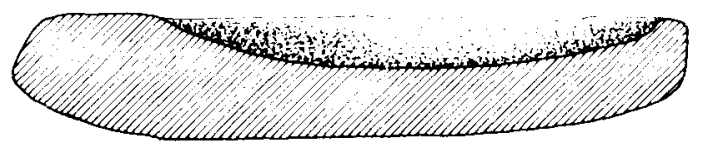

Fig. 10. Objetos líticos característicos: 1. Hoja simple; 2. Microlito geométrico; 3 . Hojija; 4. Punta de flecha; 5. Hoja retocada; 6. Idolo tipo Argalo; 7. Molino. 
ralizadora que sólo podrá corregirse o concretarse a medida que progresen las investigaciones en este campo de la Prehistoria.

Podemos contemplar la presencia bastante generalizada en zonas diversas del Noroeste de ciertos artefactos de piedra pulida (hachas, azuelas, microhachas, cuentas), tallada (geométricos, hojitas, lascas, algunas hojas) o del grupo de varios (molinos, guijarros) como indicios de un primer momento del megalitismo, a fines del IV milenio y comienzos del III (en cronología radiocarbónica convencional), muy bien representado en varios túmulos de la sierra de Aboboreira pero cuyos rasgos podemos rastrear con mayor o menor fidelidad en otras regiones: Trasos-Montes (Pena Mosqueira 3), litoral occidental gallego (As Rozas, parte del material de Chan da Cruz, tal vez algún monumento de corredor incipiente como As Pereiras) o valle del Miño (Abelleira 2, Monte da Morá 7). Naturalmente, esta panorámica posiblemente encubre particularidades (en el plano arquitectónico, sin ir más lejos) existentes en zonas diferentes de un territorio tan amplio como el considerado. Por otro lado, la visión de conjunto aparece emborronada por la documentada pervivencia de algunos de los materiales de tradición antigua, así como por la reutilización tardía de ciertos monumentos de indudable construcción arcaica (v. g. Chan da Cruz o Mina do Simâo) pero, a pesar de estos inconvenientes y limitaciones, creemos que en diversas zonas del Noroeste puede detectarse bajo distintas soluciones arquitectónicas (cámaras poligonales simples, túmulos sin cámara o incluso tal vez algún sepulcro de corredor) un tipo de material lítico, de "tradición epipaleolítica» ${ }^{37}$ en unos casos y claramente neolítica en otros, que senala una etapa primigenia del fenómeno megalítico regional.

Los 34 túmulos sitos en la franja costera representan un $39 \%$ de todos los yacimientos cuyos materiales hemos catalogado. Sin embargo, al examinar la riqueza o la variedad artefactual, encontramos que en cuanto al primer aspecto hay 15 monumentos costeros que pasan de la media (los del interior son 14), siendo 16 los que están por encima de ésta por lo que atañe a variedad (en el interior son 18). Esto significa que más de la mitad $(52 \%)$ de las sepulturas más ricas se ubican en la zona costera, acercándose a dicha proporción (47\%) dentro del grupo de las que presentan una mayor variedad en su panoplia lítica. Aunque la dicotomía detectada en este estudio entre áreas litorales e interiores puede muy bien remontarse a los inicios del fenómeno megalítico o in-

${ }^{37}$ Utilizamos este término con reservas dado el escaso conocimiento que se posee en el Noroeste sobre las etapas preneoliticas. 
cluso a etapas anteriores, creemos que puede haberse acentuado ya dentro del III milenio, posiblemente en fechas no muy anteriores a los mediados de éste. Sería en este momento cuando se generalizaría la costumbre de depositar en los sepulcros puntas de flecha, grandes hojas $o$, de forma menos frecuente, elementos tales como bolas y puntas de piedra pulida.

Tanto las puntas de flecha como las hojas de gran tamaño aparecen en cantidades muy superiores y con más frecuencia dentro de túmulos de localización costera, evidenciando no sólo unas pautas rituales probablemente distintas de las existentes más al interior, sino también una mayor capacidad de movilización de recursos por parte de las comunidades residentes en el litoral, particularmente de una materia prima que como el silex -empleado en la fabricación de casi la mitad de las puntas de flecha y de todas las hojas - es sumamente rara en el Noroeste y cabe considerarla virtualmente como un material de lujo, implicando con gran probabilidad el establecimiento de intercambios con áreas exteriores, al menos para la obtención de núcleos aptos para la extracción de largas hojas ${ }^{38}$. Este intercambio de ámbito intercomarcal o interregional no tiene que iniciarse necesariamente en esta etapa sino que, a menor escala, sus comienzos pueden remontarse a momentos anteriores, como podría evidenciar la antigüedad de la elaboración de cuentas en variscita, una materia prima de distribución muy restringida dentro del cuadrante noroccidental peninsular.

Posiblemente hacia el último tercio del III milenio se produce un desarrollo cuyos rasgos más puros se localizan hoy por hoy prácticamente en exclusiva dentro de la orla costera occidental de Galicia. La característica más típica vendria dada por la aparición de ídolos tipo Argalo, acompañados o no por ídolos-guijarro, en sepulcros de corredor complejo que contienen generalmente ajuares de una especial variedad en elementos de piedra tallada o pulida. Algunas sepulturas localizadas al interior reflejan de forma más modesta estas nuevas tendencias en el plano ritual, con el hallazgo aislado de algún ídolo tipo Argalo (mamoa da Touta) o de otras variedades (Madorras 1, Abelleira 2).

${ }^{38}$ Tenemos un ejemplo excepcional de la probable llegada de silex desde el mundo megalitico del Sur del Duero, esta vez en forma de una pieza ya acabada, en la alabarda encontrada en San Juan de Parada (Lugo), desgraciadamente fuera de contexto (ARIAS VILAS, F., y VAzOUEz VARELA, J. M., "Una alabarda de silex hallada en San Juan de Parada", Boletin de la Comisión Provincial de Monumentos Históricos y Artisticos de Lugo, 9, 19741975. págs. $184-186$ 
Mientras en algunas zonas del interior la impresión -mediatızada por la escasez de excavaciones modernas en dichas áreas- que se obtiene a través de los ajuares líticos es de un cierto continuismo, en el área integrada fundamentalmente por el valle alto del Miño, con prolongaciones hacia las serranias situadas al Norte y Oeste, se concentran una serie de sepulturas tumulares mal conocidas que contienen ajuares muy escasos en elementos de piedra tallada (en especial útiles retocados), pero, sin embargo, particularmente ricos en artefactos de piedra pulida, algunos de los cuales son casi exclusivos de esta zona y se asocian entre si con frecuencia (mazas, dobles azuelas, dobles hachas, cinceles y láminas de azada) (lám. 1). La fuerte personalidad de la región mencionada parece ser un fenómeno de configuración tardía y aunque la cronología exacta es dificil de establecer, parece razonable que haya que fijarla en las postrimerias del III milenio o comienzos del II. Hay otros materiales igualmente tardios, cuya aparición se restringe a esa misma área, como los discos Rechaba o los discos perforados, pero al menos los segundos parecen encuadrarse en contextos tumulares claramente diferenciados de aquéllos albergando mazas u otros artefactos asociados. 


\section{BIBLIOGRAFIA}

ALMEIDA, C. A. B., "Carta arqueológica do concelho de Esposende", Boletím Cultural de Esposende, 9-10, 1986, págs. 39-59.

Arias Vilas, F., y VAzQUez VARELA, J. M., "Una alabarda de sílex hallada en San Juan de Parada", Boletín de la Comisión Provincial de Monumentos Históricos y Artisticos de Lugo. 9, 1974-1975, páginas 184186.

Bello Diéguez, J. M., "Monumento megalítico de Dombate». Arqueoloxía-Informes, 1, 1989, págs. 24-30.

Bouza Brey, F.; Carro Otero, J., y Garcia Martinez, C., «Excavación de túmulos dolménicos en San Andrés de Lousada (Lugo)", Noticiario Arqueológico Hispánico, Prehistoria, 2, 1973, págs. 39-55.

Criado Boado, F., y Fabregas Valcarce, R., "The megalithic phenomenon of NW Spain: main trends", Antiquity, 63, 1989, págs. 682696.

Criado Boado, F., "Megalitos, espacio, pensamiento", Trabajos de Prehistoria, 46, 1989, págs. 75-98.

Cruz, D. J., "Excavaçâo da Mamoa do Monte da Olheira", Arqueologia, 13, 1986, págs. 125-139.

- "O megalitismo do Norte de Portugal», Trabalhos de Antropologia e Etnologia, 28, 1988, págs. 15-41.

Cruz, D. J., y VILACA, R., "Trabalhos de escavaçâo e restauro do dólmen 1 do Carapito", Trabalhos do Instituto de Antropologia, 45, Oporto, 1990, 23 págs.

Delibes de Castro, C.; Alonso Diez, M., y Galván Morales, R., «el Miradero: Un enterramiento colectivo tardoneolítico de Villanueva de los Caballeros", Estudios en Homenaje al Dr. Antonio Beltrán Martinez, Zaragoza, 1986, págs. 227-236. 
Fabregas VALCARCE, R., "Cronología y periodización del megalitismo en Galicia y Norte de Portugal», Espacio, Tiempo y Forma - Prehistoria, 1, 1988, págs. 279-291.

- Estudio de los ajuares líticos de las sepulturas megalíticas de Galicia y Norte de Portugal, Tesis Doctoral inédita, Madrid, 1990.

Faro, S.; Cleto, J., y CARneiro, A. L., "A escavaçâo da mamoa de Outeiro no contexto do campo arqueológico da Serra da Aboboreira», Trabalhos de Antropologia e Etnologia, 28, 1988, págs. 251-262. GonçAlves, A. H. B., "Excavaçâo da mamoa da Touta", Arqueologia, 17, 1988, págs. 58-72.

- "Sabrosa-Nótula Arqueológica», 1. Congresso Internacional sobre o rio Douro, Vila Nova de Gaia, 1986, pág. 107.

JoRge, V. O., y Bettencourt, A. M. S., «Sondagens arqueológicas na mamoa 1 de Châ de Parada", Arqueologia, 17, 1988, págs. 73-118.

JORGE, V. O., "Arqueologia social dos sepulcros megalíticos atlânticos: conhecimentos e perspectivas actuais", Revista da Faculdade de Letras, 6, 1989, págs. 365-443.

- "Campo arqueológico da Serra da Aboboreira. Arqueologia do concelho de Baiâo. Resultados de 10 anos de trabalho, Arqueologia, 17, 1988, págs. 5-27.

- "Escavaçâo da mamoa da Mina do Simâo", Arqueologia, 9, 1984, págs. 3-21.

- Megalitismo do Norte de Portugal: O distrito do Porto. Os monumentos e a sua problemática no contexto europeu, Tesis Doctoral inédita, Oporto, 1982.

LEISNER, G., Verbreitung und Typologie der galizischnordportugiesischen Megalithgräber, Marburg, 1938.

Leisner, V., y Ribeiro, L., "Die Doimen von Carapito", Madrider Mitteilungen, 9, 1968, págs. 11-62.

LOPEz Cuevillas, F., “La época megalítica en el Noroeste de la Península», Caesaraugusta,, 13-14, 1959, págs. 21-77.

Patiño Gómez, R., "Excavación de la mámoa 1 de Chan da Cruz", Pontevedra Arqueológica, 1, 1984, págs. 17-38.

- "Excavación de la mámoa núm. 1 de As Rozas", Pontevedra Arqueológica, 1, 1984, págs. 45-68.

Peña Sanchez, D., Estadística. Modelos y métodos, Madrid, Alianza Universidad Textos, 1987.

Rodriguez Casal, A.-A., «A mámoa de Monte Campelos e o seu enterramento secundario. Novos datos encol do Megalítico Final galego", en Boletín do Museo Provincial de Lugo, 1, 1983, págs. 7-17.

- «La necrópolis megalítica de Parxubeira. Campañas arqueológicas de 1977 a 1984", Monografías Urxentes do Museu, 4, La Coruña, 1989. 
SANCHES, M. de J., "A mámoa 3 de Pena Mosqueira", Arqueologia, 15 , 1987, págs. 94-115.

SHeE TWOHIG, E., The megalithic art of Western Europe, Oxford, Clarendon Press, 1981.

SILVA, E. J. L. da, "A mamoa de Afife: breve síntese de 3 campanhas de escavaçâo", Trabalhos de Antropologia e Etnologia, 28, 1988, págs. 127-132.

SiLva, F. A. P. da, "A mamoa 2 da Serrinha», Arqueologia, 6, 1982, págs. 19-31.

Vizmanos, J. R., y Asensio, R., Curso y ejercicios de bioestadística, Madrid, Centro de Promoción Reprográfica, 1976. 